NBER WORKING PAPER SERIES

\title{
TIME SERIES DECOMPOSITION AND MEASUREMENT OF BUSINESS CYCLES, TRENDS AND GROWTH CYCLES
}

\author{
Victor Zarnowitz \\ Ataman Ozyildirim \\ Working Paper 8736 \\ http://www.nber.org/papers/w8736
NATIONAL BUREAU OF ECONOMIC RESEARCH
1050 Massachusetts Avenue
Cambridge, MA 02138
January 2002

Zarnowitz: Senior Fellow and Economic Counselor, The Conference Board; Research Associate, National Bureau of Economic Research; and Professor Emeritus of Economics and Finance, University of Chicago. Ozyildirim: Economist, The Conference Board. First version of this paper was prepared for the meeting of The Conference Board Business Cycle Indicators Program Advisory Panel, March 3, 2000. We have benefited from discussion by members of The Conference Board Business Cycle Indicators Program Advisory Panel, and are particularly grateful to James K. Stock for his Comment and permission to use it in the present version of the paper. We thank James Morley and Julio Rotemberg for providing computer programs for trend estimation. Of course, all remaining errors are ours. The views expressed herein are those of the authors and not necessarily those of the National Bureau of Economic Research.

(C) 2002 by Victor Zarnowitz and Ataman Ozyildirim. All rights reserved. Short sections of text, not to exceed two paragraphs, may be quoted without explicit permission provided that full credit, including $($ C notice, is given to the source. 
Time Series Decomposition and Measurement of Business Cycles, Trends and Growth Cycles Victor Zarnowitz and Ataman Ozyildirim

NBER Working Paper No. 8736

January 2002

JEL No. E32, N10, O47

\begin{abstract}
A study of business cycles defined as sequences of expansions and contractions in the level of general economic activity does not require trend estimation and elimination, but a study of growth cycles defined as sequences of high and low growth phases does. Major cyclical slowdowns and booms deserve to be analyzed along with classical recessions and expansions, but the needed time series decomposition presents difficult problems, mainly because trends and cycles influence each other. We compare cyclical movements in levels, deviations from trend, and smoothed growth rates of the principal measures of aggregate economic activity - the quarterly real GDP and the monthly U.S. Coincident Index - using the phase average trend (PAT). Then we compare alternative trend estimates, deterministic and stochastic, linear and nonlinear, and the corresponding estimates of "cyclical components," that is, series of deviations from these trends. We discuss how these measures differ in terms of the patterns, timing, amplitudes, and smoothness of the resulting estimates of U.S. growth cycles in the post-World War II period. The results of PAT show great similarity to the results obtained with the H-P and band-pass filtering methods, but in matters of detail PAT is often superior.
\end{abstract}

Victor Zarnowitz

Senior Fellow and Economic Counselor

The Conference Board

845 Third Avenue

New York, NY 10022

and NBER

victor.zarnowitz@conference-board.org

\author{
Ataman Ozyildirim \\ Economist \\ The Conference Board \\ 845 Third Avenue \\ New York, NY 10022 \\ a.ozyildirim@conference-board.org
}




\section{Background, Motivation and Plan of This Study}

Recent empirical research on business cycles devotes much attention to time series adjusted for long-term growth trends. This is in contrast to the early studies which defined business cycles as sequences of expansions and contractions in a large array of series representing the levels of total output, employment, and many other component and related processes. It is the mild or severe absolute declines in general economic activity (recessions or depressions) that are of particular concern to economic agents and observers. The expansions and contractions in the level series could be analyzed without trend adjustments. This was the position taken by the "classical cycle" approach dominant particularly in the studies of the National Bureau of Economic Research (NBER).

For a number of reasons to be discussed, it is difficult to estimate and eliminate growth trends from economic aggregates and their components, and faulty trend estimates can cause significant errors. When no trend adjustments are required, the analysis can be comparatively simple and reliable. This is an additional reason why studies of cyclical indicators, at the NBER, the U. S. Department's of Commerce Bureau of Economic Analysis (BEA), and most recently The Conference Board (TCB), concentrated on timing and other aspects of non-seasonal fluctuations in series that in many cases show pronounced long-term trends.

Much can be, and indeed much has been, accomplished by following this approach. Intensive and detailed studies of a large number of diverse indicators laid the foundation for much of the existing knowledge of "what happens during business cycles" (Mitchell 1951). Thus, discovery of comovements and timing characteristics led to the 
dating of business cycles and the distinction between groups of leading, coincident, and lagging indicators.

But the economy has at times suffered major slowdowns, that is declines not in levels but in growth rates that remain positive. It is certainly possible to conceive of a severe and long slowdown causing more hardship than a mild and short recession. Even though such slowdowns are rare, sequences of serious acceleration and deceleration of macroeconomic activity have long attracted considerable public and professional concern. These "growth cycles" can be measured as fluctuations in the deviations of the principal indicators around their generally rising trends. So trend estimation, which is not needed for business cycle analysis, cannot be avoided in growth cycle analysis. ${ }^{1}$

Clearly, all recessions involve slowdowns, but not all slowdowns involve recessions; hence, growth cycles are more numerous than business cycles. Of course, the two sets of phenomena or processes are related, but they are distinct as defined and measured. Yet some of the recent papers proposing different detrending methods, which yield various growth cycle estimates, mistakenly seek verification in NBER chronologies or other measures relating to business cycles. What is frequently implied is that growth cycles and business cycles are not distinguishable, and slowdowns are treated like recessions. $^{2}$

One can only welcome the revival of interest in methods of filtering and detrending economic and financial indicators that is associated with recent research in business cycles. However, these methods too often abstract from the main difficulty of

\footnotetext{
${ }^{1}$ As will be shown in section 2.4 below, using fluctuations in smoothed growth rates is not a good substitute.
} 
time series decomposition, which is that trends and cycles interact and influence each other, as suggested by the literature and data. Also, there is much diversity and uncertainty about which indicators are to be used to define cyclical movements. The NBER chronology of business cycles, which is widely accepted, is based on the consensus of coincident indicators of production, employment, real income and real sales. Both comovements and persistence are key characteristics of business cycles. They are to a large extent present in major fluctuations of economic and financial time series after trend elimination as well.

Despite the rather rich background of past and contemporary work, then, there is much in this area that needs to be clarified and improved. Our intention and hope here is to remove or at least reduce the sources of confusion in studies of economic fluctuations. This provides the basic motivation for the paper in which we focus on practical needs of research in the indicators of cyclical turning points and movements. How do the different approaches to trend estimation compare from this point of view?

The paper has two substantive parts. Part 2 shows how the study of business cycles, i.e., movements measured in time series that may include trends, is complemented by the study of growth cycles, which applies parallel criteria and methods to the same indicators series adjusted for longer-term trends. We explain the so-called "phase average trend" (PAT) used for this purpose, then examine the possibility of using smoothed percentage changes to measure growth cycles. The data used, rules observed, and problems encountered in this work are discussed using the resulting chronologies for the United States in the post-World War II period.

\footnotetext{
${ }^{2}$ For a recent debate on how "business cycle facts" are reflected in selected detrended aggregates, see Canova (1998a, 1998b, 1999) and Burnside (1998). For views similar to ours see Harding and Pagan
} 
Part 3 asks how useful are other approaches to time series decomposition for the analysis of growth cycles. We proceed from linear deterministic to linear stochastic trends, from unobserved component models to the Hodrick-Prescott, heuristic and bandpass filter methods of trend estimation. A comparative analysis of these methods along with PAT suggests that the latter yields on the whole better results for the purposes of identification and study of growth cycles. The last section of the paper collects and states briefly our main inferences and conclusions.

\section{Cyclical Movements in Levels, Deviations from Trend, and Growth Rates}

\subsection{Business Cycles and Time Series Components}

In the traditional NBER approach, the business cycle included the intra-cycle trend. Secular forces were believed to influence the cycle and cyclical forces were believed to influence the trend in a way making an adequate, clean separation of cycle and trend impossible. A step function linking the average levels of a variable in successive business cycles was effectively the trend representation complementing the cyclical measures. ${ }^{3}$

In the so defined "classical" business cycles, expansions should tend to be longer and larger than contractions, but either phase must be persistent and pervasive enough to allow for the significant cumulative and interactive effects that are observed and analyzed in literature. The sequence of up and down phases that constitutes the business cycle is recurrent but not periodic. According to Burns and Mitchell (1946), business cycles vary

\footnotetext{
(1999).

${ }^{3}$ Burns and Mitchell (1946, ch. 7) conclude that trend adjustments reduce the variations of cyclical behavior both across series and within series over time. They regard that as a disadvantage because these variations matter in the analysis of business cycles (pp. 307-309).
} 
in duration "from more than one year to ten or twelve years". This would still

accommodate all the cycles identified so far, domestic and foreign, but the more typical range for the U.S. is not so broad, since very few cycles are shorter than two or longer than eight years (however, the duration of business expansions may be increasing). ${ }^{4}$

We accept the NBER definition and the view that seasonally adjusted level data rather than detrended data should be used for the analysis of business cycles under the time-honored definition of recessions and recoveries. Yet, this is not the only interesting concept of generalized economic fluctuations.

In the traditional NBER approach, each monthly or quarterly time series was treated as a product (or, less likely, a sum) of three components: the seasonal (S), the irregular (I), and the trend-cycle (TC). ${ }^{5}$ After elimination of S, a combination of smoothing formulas served to reduce the effects on TC of the multitude of short, randomly distributed irregular (I) movements and to identify the turning points. However, no attempt was made to segregate and eliminate the effects on longer movements of major episodic disturbances due to wars, strikes, industrial combinations and conflicts, technological innovations, abundant or poor harvests, etc. (Bry and Boschan 1971, see esp. ch. 3). The risk that excessive or inappropriate smoothing may

\footnotetext{
${ }^{4}$ According to the historical NBER chronology for the United States, which goes back to 1796 (annual before 1854, monthly thereafter), only four of the 45 peak-to-peak cycles exceeded eight years or 100 months, and only two were shorter than two years or 20 months. This count includes the last cycle with the initial peak at July 1990 and the trough at March 1991, whose expansion lasted ten years to March 2001. It deserves to be noticed that the three longest cycles occurred recently, in the 1960s, 1980s and 1990s. Business cycles in Europe have been longer than in the U.S., averaging about five instead of four years. (See Moore and Zarnowitz 1986 and Glasner, ed. 1997, Appendix.)

${ }^{5}$ On the treatment of seasonal variations in the NBER program of studies in business cycles (see Burns and Mitchell 1946, pp. 43-55). Great care would be exercised in the estimation of seasonal variations, using the best available methods that are still dominant, albeit in significantly improved form (see Shiskin, Young, and Musgrave 1965). The intrayear S oscillations depend more on exogenous factors (weather, customs, etc.) and tend to be well distinguishable from the other components, which are either shorter and more erratic (I) or longer and smoother but less systematic (TC). Hence, the seasonal adjustments needed for
} 
distort the measured fluctuations or even create spurious ones was recognized early in NBER studies (see Macaulay 1931; Burns and Mitchell 1946, ch. 8).

Early work on secular movements at the NBER was motivated by interest either in economic growth per se or in how growth affects business cycles (Kuznets 1930; Burns 1934; Macaulay 1938; Burns and Mitchell 1946, ch. 7). Here the preference was rather clearly for trends that are flexible and smooth, particularly in the literature relating to the effects of trends on cyclical behavior. Most of the estimated trends were nonlinear, some were non-monotonic, even oscillatory; the design was to make their steepness and curvature depend on the data.

Not surprisingly, the NBER studies favored working with data-based rather than model-based procedures, e.g., with moving averages rather than time-series models. This helps explain the choices on measuring growth cycles and trends made by Mintz (1969, 1972) and by Boschan and Ebanks (1978). This work first formalized the concept and estimation of the phase average trend (PAT) to be used in the analysis of fluctuations in detrended indicators and indexes. A major task of this paper will be to discuss PAT in some detail and compare it with other trends. First, however, the rationale of the approach must be considered by asking why fluctuations in detrended series need to be studied after all.

cyclical analysis (and other purposes), although far from trivial statistically, were believed to be relatively tractable. 


\subsection{Why Trend Adjustments Are Needed}

We have argued that studies of business cycles can go a long way without requiring trend estimation and elimination. Yet the trend-cycle decomposition is needed for several reasons and is not intractable.

First, reasonably good trend estimates are required to study economic growth empirically and test related theories. This task cannot be accomplished without sufficiently long and reliable data and without confronting the question of how trends and cycles influence each other. We list this point first because of the dominant importance of economic growth and its major sources (notably productivity) for the society's wellbeing. But our principal research interest here is in how best to isolate growth and fluctuations, not in how to measure secular trends and their welfare effects.

Second, in the first two post-World-War II decades -- an era of reconstruction, democratization, foreign aid, and important monetary, fiscal and structural reforms -several countries in Europe and the Far East, notably West Germany and Japan, enjoyed very high rates of real growth. These expansions were interrupted by retardations rather than absolute declines in overall economic activity. The same applies to more recent expansions in some developing countries such as India. ${ }^{6}$ In the absence of business cycle recessions, sequences of slowdowns and speedups of substantial size, spread, and length attracted considerable public attention in many advanced and developing market-oriented economies. These "growth cycles" or "deviation cycles" were formally identified and

\footnotetext{
${ }^{6}$ It is well to note that historical studies identified business cycles in the past for a number of the same countries, including Japan, India, and of course Germany. See Thorp 1926.
} 
dated for many countries. ${ }^{7}$ Measurement and analysis of cycles in the deviations from trend constitute a very worthwhile subject for the light they may throw on (a) the level and variability of growth, and (b) the sources of economic instability.

Third, the appraisal of cyclical indicators can be substantially improved by considering their trends and the fluctuations in the deviations from trends. Leading indicators are much more sensitive to all types of disturbances, whether associated with business cycles or with fluctuations at shorter frequencies; hence they are generally much more volatile than coincident indicators. They also have as a group fewer and weaker upward trends. The aggregate output and input, real income and sales series grow strongly, whereas some leaders such as the average workweek, unemployment claims, or the diffusion index of slower deliveries (vendor performance) are stationary or have only weak trends. Using deviations from trend or smoothed growth rates reduces these differences between the two sets of indicators.

The leaders seldom miss turning points in coinciders but they show many "extra" turns of their own not connected with business cycles. But these apparent "false signals" in leading indicators are not random: most of them are associated with turning points in growth cycles. Numerous tests confirm that most economic slowdowns of cyclical proportions have been anticipated by leading indicators, in the U.S. and abroad. Indeed, when deviations from trend are used, the series classified as leading, roughly coincident, and lagging in relation to the U.S. business cycles tend to show corresponding timing characteristics in relation to growth cycles in a number of market economies including the United States (Klein and Moore 1985).

\footnotetext{
${ }^{7}$ The first, influential study of major fluctuations in detrended indicator series was by Ilse Mintz for West Germany (1969). Her method has been applied and improved by several analysts at the NBER and adopted
} 
Growth cycles have not replaced business cycles; but we conclude that business cycle research needs to be complemented by study of trends and growth cycles.

\subsection{The Phase Average Trend}

For a monthly or quarterly series of interest (e.g., the U.S. coincident index or real GDP, both seasonally adjusted), compute deviations from a centered 75-month (25quarter) moving average and from its extrapolations at the beginning and end of the series. Break up the series into "phases", according to the dates of cyclical peaks and troughs in the deviations of the series from its moving average. Compute the mean values of the series for each successive phase, and smooth the results by means of three-item or two-item moving averages. The PAT (phase average trend) is approximated by connecting the midpoints of these "triplets" or "doublets".

The use of centered 75-month moving averages makes it necessary to extrapolate backward (forward) over the first (last) 37 months of the series covered. This is the main source of problems and errors here: note that the slope of the trend at the end of the period must be estimated while the relevant cyclical developments are still unknown. But this "end-period" difficulty is a general one, applying to all other methods of trend determination as well.

All procedures to estimate and eliminate trends are to some extent arbitrary, and PAT is certainly no exception. The method lacks the mathematical elegance or apparent simplicity of other approaches that can be summarized by formulae; however, the first

\footnotetext{
internationally, notably by the Organization for Economic Cooperation and Development (OECD) in Paris.

${ }^{8}$ The above is an attempt to summarize briefly the ten-step procedure developed in Boschan and Ebanks (1978). See the source for details.
} 
impression of it as an excessively elaborate calculation is misleading. The multi-step, successive-approximations approach is dictated by the objective of deriving estimates that reflect in a reasonable way the interplay of longer (trend) and shorter (cyclical) movements.

The resulting trend replaces the short, large fluctuations of the series with gradual and persistent movements. PAT passes smoothly through the principal segments of higher and lower average growth in the data, which makes it nonlinear and flexible.

Chart 1 shows the coincident index (CI) for the United States monthly since 1948, with shaded areas representing business cycle recessions as dated by NBER. ${ }^{9}$ This series, published since 1996 by The Conference Board, was compiled earlier by the Bureau of Economic Analysis in the U. S. Department of Commerce. It is evident that CI, which is based on the consensus of comprehensive measures of real personal income, real manufacturing and trade sales, industrial production, and nonfarm employment, had nine cyclical declines in this period, which represent well the nine recessions of 1948-91. The phase average trend of the coincident index continued to rise in each recession with what appears to be only few and weak slope changes (the trend slowdowns of the early 1980s and the early 1990 s are the most visible ones).

Chart 2 shows that the percentage deviations from PAT of the U.S. coincident index do stand out very clearly, with sharp cyclical peaks (P) and troughs (T) alternating on the plus and minus sides of the zero line, respectively. The shaded columns represent the cyclical slowdowns dated according to these P's and T's. The series is smooth as it is, in month-to-month movement, showing a months of cyclical dominance (MCD) ratio 
of one. (This is the ratio of cyclical to irregular components on the average, see Bry and Boschan 1971.)

The dates of the fourteen U.S. growth slowdowns completed between 1948 and 2000, as determined from the PAT deviations for CI according to the algorithm developed by Bry and Boschan (1971), are listed in Table 1, along with the durations of the corresponding above-trend and below-trend phases (columns 1-6). The table also includes a parallel listing of the turning dates and durations for the nine U.S. business cycles of the 1948-2001 period. It is clear that growth cycles are generally shorter, more frequent, and much more nearly symmetrical than business cycles; they vary less (but still appreciably) by duration. This is because long business cycle expansions are usually interrupted by significant slowdowns. These slowdowns give rise to additional declines in the detrended aggregates when compared with the original declines in the levels of the same series. In addition, most postwar recessions were preceded by marked retardations of growth. ${ }^{10}$

Chart 3 shows that real GDP declined around the same dates as the CI, although not necessarily in two or more consecutive quarters; this popular rule of thumb would clearly have failed in some of the recent recessions. The deviations from PAT for real GDP shown in Chart 4 follow closely the pattern of growth cycles derived from the data for the U.S. coincident index. This close correspondence is not surprising, since the cyclical movements in the coincident index are well correlated with those in real GDP.

\footnotetext{
${ }^{9}$ The Conference Board publishes the U.S. coincident index for the period starting in January 1959. The coincident index used in this paper was extended back to January 1948 with the component data from the Business Cycle Indicators Database maintained by The Conference Board.

${ }^{10}$ Note that the Bry and Boschan algorithm identifies a peak in March 1998 and a trough in September 1999. We did not use this peak-trough pair in our analysis since it is uncertain whether it qualifies as a growth cycle contraction; the deviations from PAT were not negative in the coincident index and were only briefly negative in real GDP.
} 
Note that the upward trend in Chart 3 crosses the real GDP curve approximately at the mid-points of each of the nine business cycle contractions of the period covered (marked by shaded areas). Chart 4 demonstrates that the series of percentage deviations from the trend declined strongly during the recessions of 1949, 1953, 1957, 1960, 1970, 1973-75, and 1981-82, less so during the milder and shorter recessions of 1980 and 199091. In addition, smaller declines in the PAT detrended real GDP occurred in 1952, 1962 63, 1966-67, 1984-87, and 1994-96: all slowdowns interrupting long economic expansions. ${ }^{11}$

\subsection{Cycles in Smoothed Growth Rates vs. Deviations from Trend}

PAT was applied at the NBER to a large number of indicators with generally satisfactory results. Still, students of growth cycles have long been fully aware that the selection of the trend curve is inevitably associated with considerable arbitrariness. This is why Friedman and Schwartz (1963) and Mintz (1969) looked for an alternative to detrending by attempting to identify cyclical fluctuations in series of growth rates directly.

There are two major problems with this approach. First, growth rates computed over short unit periods tend to be very erratic for many monthly and even quarterly indicator series. Thus, the growth series, even when derived from strongly cyclical level series, often have dominant irregular components, which obscure their underlying cyclical movements. To bring out the latter, the series must be smoothed with fairly long

\footnotetext{
${ }^{11}$ Working with related but earlier and inferior methodology, Ilse Mintz found that most detrended indicators for Germany in 1950-67 displayed "clear-cut cyclical swings with unmistakable turning points" (1969, p. 14). The set of centered 75-month moving averages could do at least rough justice to these diverse time series, something that according to Mintz "could not have been done with fitted trends," and
} 
and/or complex moving averages. But this procedure runs a certain risk of distorting the patterns, and perhaps especially the timing, of these movements; it calls for careful handling of the data and caution in interpreting the results.

The second perceived problem is the timing of the growth rates, which is very different from that of the corresponding level series. Early in an expansion growth is usually high, starting as it does from a low base after a period of decline. As the base itself rises during the expansion, growth rates fall lower and lower. Hence, cycles in growth rates can be expected to lead cycles in levels at peaks. Mintz (1969, p. 15) argued that these leads at downturns are so long (between one half and nearly one full business expansion phase) as to invalidate the use of peaks and troughs in growth rates for dating purposes. Instead she proposed to define the downturn in a growth cycle as the end of a period of relatively high growth and the upturn as the end of a period of relatively low growth. These are the "step-cycles" introduced earlier by Friedman and Schwartz in their 1963 work on the cyclical behavior of money. ${ }^{12}$

Despite much informative work on step cycles, the concept has not caught on, and for good reasons. Most series of rates of change, when smoothed, show cyclical fluctuations similar to those in detrended values; they do not move in steps. (Unsmoothed, they are often very irregular or jagged, as already noted.) Thus, as noted

the methods succeeded in distinguishing well between leading, coincident, and lagging indicators (ibid. pp. 12 and 28-43).

${ }^{12}$ With the average rate during a high step exceeding systematically the average rate during the preceding and succeeding low steps, they found the resulting cycles to correspond closely to the cycles in the trend adjusted series proper. Mintz, using a computerized version of the Friedman-Schwartz method, also concludes that deviation cycles and step-cycles show a high degree of agreement, particularly for composite indexes and at "strong turns." (For individual indicators and at weak, i.e., not well articulated turns, the correspondence is at times attenuated.) For evidence, see Mintz 1969 and 1972, tables and charts for West Germany and the United States, respectively. The turning points between the steps are determined by a program that maximizes the difference between the corresponding step variances. For the U.S., the turns in deviation cycles and in step cycles are approximately coincident in three-quarters of the cases. The worst matchings are related to the occurrence of flat bottoms and ceilings or of double turns. 
by Moore (in Zarnowitz 1972, pp. 178-9), “The step-fitting operation...seems to be imposing on the data something that is not obviously there."

As Chart 5 shows, using simple year-over-year change in the coincident index (call it CIGY) produces a series that falls in each shaded period and rises in each unshaded period, where the shadings are dated according to the cyclical declines in the detrended value of the index (to be labeled CIDPAT). The patterns of movement in the two series are very similar: there is a one-to-one correspondence between their cyclical fluctuations. One easily seen difference is that CIGY moves in larger and more varied swings than does CIDPAT. The latter is approximately symmetrical around the zero line, as would be expected of deviations from trend; it seldom exceeds the range of \pm two percent. In contrast, CIGY consists largely of positive numbers, again as was to be expected; they are concentrated in the range of zero to six percent, with negative numbers limited to recessions and their immediate aftermaths in 1960, 1970, 1975, 1980, 1982, and 1991 (see chart). ${ }^{13}$

Growth rates of CI (and GDP) do indeed start falling early in expansions before the corresponding series of deviations from trend, and this relationship is systematic. Figure 1 shows how the inflection point in the level of aggregate economic activity, which is the peak in smoothed growth rate $\left(\mathrm{P}_{\mathrm{gr}}\right)$, is likely to precede the point where our schematic index exceeds most the corresponding trend, which is the peak in its detrended value $\left(\mathrm{P}_{\mathrm{dt}}\right)$. The underlying assumption is that growth starts decelerating in the vicinity of where economic activity rises above trend. The sequence on the upgrade is that $\mathrm{P}_{\mathrm{gr}}$ leads

\footnotetext{
${ }^{13}$ In retrospect, CIGY can be easily made more symmetrical by taking deviations from a sequence of averages (3.427 for $1 / 60-11 / 70,2.9595$ for $12 / 70-4 / 75,2.953$ for $5 / 75-8 / 80,2.104$ for $9 / 80-4 / 91$, and 2.677 for 5/91-12/2000). The adjustment seems fairly innocuous as it does not alter the timing of the cycles in CIGY, but it is based on hindsight and we decided not to use it.
} 
$\mathrm{P}_{\mathrm{dt}}$ which in turn leads the peak in the level of economic activity itself (BCP). Thus the downturn in the growth cycle (signaled early by $\mathrm{P}_{\mathrm{gr}}$ and identified as $\mathrm{P}_{\mathrm{dt}}$ ) tends to lead the downturn in the business cycle.

On the downgrade, a deceleration in growth may also start ahead of the time when activity falls farthest below the trend, as illustrated by $\mathrm{T}_{\mathrm{gr}}$ leading $\mathrm{T}_{\mathrm{dt}}$ in Figure 1; however, $\mathrm{T}_{\mathrm{dt}}$ may follow rather than lead the business cycle trough (BCT). We show a short lag here, but in sluggish recoveries, like that of 1991-93, $\mathrm{T}_{\mathrm{dt}}$ could be much slower in arriving. At sudden sharp downturns, growth cycle and business cycle peaks may coincide: an example is $\mathrm{P}_{\mathrm{dt}}$ and BCP' (in the second cycle shown in Figure 1). A very quick V-shaped upturn could represent at the same time all three troughs - in growth rates, deviations from trend, and levels $\left(\mathrm{T}_{\mathrm{gr}}, \mathrm{T}^{\prime}{ }_{\mathrm{dt}}\right.$, and $\mathrm{BCT}$ ' in Figure 1).

Growth rates are much more likely to lead detrended values at peaks than at troughs. Chart 5 allows ten comparisons at peaks of which seven are leads of CIGY relative to CIDPAT and three are exact coincidences. The shortest leads are three and five months long, five fall in the 9-12 months range, and the average timing is a lead of 6.2 months. Of the ten comparisons at troughs, six are coincidences, two are short leads of 2-3 months, and two are long leads of 9 months each. The average is a lead of 2.3 months.

These observations underestimate the true leads of CIGY relative to CIDPAT because the year-over-year change is not centered whereas the detrended series is. Centering would add another six months to the leads but we purposely avoid it so as to retain the most recent data for CIGY which might be helpful with the "end-period" problem of PAT (or other trend) estimation. 
The results of our (so far limited) experimentation with alternative ways of smoothing growth rates and computing trends proved encouragingly robust. Substituting a 6-month smoothed annualized growth rate (from Zarnowitz and Moore 1982) for the year-over-year change made little difference. Comparisons with trends derived by various filters discussed later in this paper yielded generally similar findings.

\section{Comparing Different Trend Estimates}

\subsection{Cyclical Analysis with Linear Deterministic Trends}

For a long time, the dominant approach to modeling growth and fluctuations in upward-drifting comprehensive series representing aspects of macroeconomic activity was to view them as a sum of a deterministic trend and stochastic deviations treated as the residual "cyclical" component. For example, on the assumption of exponential longterm economic growth, a linear trend would be fitted to the log of real GDP. The deviations from this trend should then be themselves stationary; the economy's output should exhibit reversion to the trend; and the effect of shocks to this trend-stationary (TS) model, though they may persist over time, should decline and eventually die out. ${ }^{14}$

A linear deterministic trend is, of course, free of any cyclical or stochastic shortterm movements. Such a clean separation of the long and short time-series components would be just fine if it were empirically acceptable. Unfortunately it is not. Indeed, it is very unlikely that any given type of linear deterministic trend would persist over long

\footnotetext{
${ }^{14}$ Let $Q_{t}=a+b t+\rho(L) \varepsilon_{t}$, where $Q=\ln$ real GDP, $L$ is the lag (backshift) operator $L^{k} Q_{t}=Q_{t-k}$, and $\mathcal{E}_{t}$ is a white noise innovation. The polynomial $\rho(L)$ must satisfy the stationarity and invertibility conditions; in a TS model, the sum of autoregressive coefficients $\sum_{i=1}^{k} \rho_{i}$ in $\rho(L)$ is less than one.
} 
stretches of time, surviving major structural and technical changes, wars, business expansions and contractions, financial crises, rising and falling inflation, etc. Surely cataclysms such as the World Wars and the Great Depression affected economic trends substantially, but so did probably for some time other positive and negative developments (e.g., the long U.S. expansions of the 1960s and 1990s as well as the great inflation between).

From the point of view of cyclical analysis, the cost of using a linear trend is that the deviations from it contain indiscriminately all business-cycle, growth-cycle, and shorter irregular movements combined. Thus, too much of the overall variation is attributed to business cycles. Moreover, the linear trends do a poor job of differentiating between good and bad economic times.

To provide evidence for the above statements, consider the log-linear trend fitted to real GDP in Chart 6 and the deviations from it shown in Chart 7. The data run below the trend line in four periods: 1959-Q1 1965; 1975; Q4 1981 - Q11984; and Q4 1990 Q1 1999. These include some sluggish times such as all or some of the recessions in 1960-61, 1975, 1981-82, and 1990-91, but also some times of good economic growth and prosperity in the early 1960s, mid- 1980s, and especially the 1990s. The data run above the trend line in three periods: Q2 1965 - Q4 1975; 1976 - Q3 1981; and Q2 1984 - Q3 1990. These include the wartime boom of the late 1960s; all of the turbulent, inflationary 1970s (except 1975), which witnessed two recessions; a short recession and an incomplete recovery in 1980-81; and the post-recovery part of the expansion of the 1980s. 
A method that shows the troublesome 1970s in a very positive light (strongly above-trend) and the prosperous 1990s in a rather negative light (continuously belowtrend) is quite difficult to accept. In each below-trend period, the economy was most of the time in a fast growing mode. Conversely, the above-trend periods include three of the six recessions covered (1969-70, 1973-74, and 1980). Furthermore, the deviations from this trend miss or underrepresent some of the growth slowdowns as in 1962-64, 1966-67, and 1984-86 (compare charts 2 and 7). ${ }^{15}$

\subsection{Modeling with Linear Stochastic Trends}

In the 1980s, a sequence of influential papers reported favorably on the hypothesis of a single (positive, real) unit root in autoregressive representations of macroeconomic variables such as real income, output, and employment. In the newly popular alternative to the TS model, a difference-stationary (DS) process was inferred from the failure to reject the unit-root model. Autoregressive integrated moving-average (ARIMA) models were applied to reduce the time series to stationarity, replacing the assumption that the series are stationary around their trends. In the DS model, there is no time trend, only a constant and a stationary and invertible ARMA term. ${ }^{16}$ As argued by Nelson and Plosser (1982), if important economic aggregates have a DS representation then they have no tendency to return to linear trends. Rather, they have "permanent components" that show no such trend reversion as they reflect shocks which have long

\footnotetext{
${ }^{15}$ Loglinear trend fits better long series of U.S. real GNP per capita (1909-1970), as shown in Diebold and Senhadji (1996), but these are annual data not well suited for study of business cycles.

${ }^{16}$ Consider the equation in footnote 14: in the DS case, $\mathrm{b}=0$ and $\sum_{i=1}^{k} \rho_{i}=1$ as implied by $\rho(L)$ containing one unit-root.
} 
persistent effects. The trend is stochastic, perhaps simply exponential plus a random error. $^{17}$

We agree that the linear deterministic trends are inadequate, as already demonstrated. Trends are indeed variable because of interactions with shorter fluctuations as well as structural breaks. However, this points to the need to make the trends nonlinear or at least piecewise linear, but not necessarily stochastic. To be useful, trends should be smooth and, in the case of variables that represent real economic growth, predominantly positive. (Severe and long depressions, which are rare, qualify as most likely exceptions). But an estimate of stochastic trend includes not only the long-term growth but also the major up-and-down movements. The latter are due to the random component of the trend, and the proponents draw a strong conclusion, namely that "permanent innovations account for a substantial fraction of transitory economic fluctuations," (King, Plosser, Stock, and Watson 1991, p. 834).

Chart 8 shows the stochastic trend obtained by applying the Beveridge-Nelson decomposition to the monthly data on the U.S. coincident index (1948-2000). ${ }^{18}$ Chart 9 shows the cyclical component of the coincident index estimated by this procedure and compares it with the shaded areas based on the deviations of CI from its phase average trend $(\mathrm{PAT})$. The detrended series in chart 9 is smooth $(\mathrm{MCD}=1)$ and roughly symmetric around zero. It shows declines during all of the growth slowdowns and recessions but some of these declines are poorly articulated, very small and mainly or entirely on the positive side of the zero line ((1962-63, 1995); some others are larger but

\footnotetext{
${ }^{17}$ For $\mathrm{k}=1$ (the first-order autoregression), the DS model reduces to a (generally geometric) random walk with drift.
} 
also mainly or entirely on the positive or negative side only $(1951-52,1960,1981-82)$.

Thus, there is no expected transition from above to below trend and so several large

fluctuations in this detrended series resemble business cycles more than growth cycles

(1949-54, 1960-70, 1975-82, and 1982-91).

We found before that linear deterministic trends leave too much of the variation in the economic times series to business cycles; now we find that linear stochastic trends include much of the fluctuations and leave too little to business cycles. ${ }^{19}$

However, careful statistical re-examinations of the subject conclude that there is simply no convincing evidence of the DS model outperforming the TS model and of the linear stochastic trends providing satisfactory estimates of the behavior over time of aggregate real variables (see part III of Diebold and Rudebusch 1999). Series that look like DS can originate in TS processes with roots close to but distinct from one, and finitesample tests cannot conclusively distinguish between DS and TS series in such cases. Not only that, but the tests display little power against TS models that are well estimated from the data and even favor such TS models when based on long spans of annual data. Point estimates of persistence of innovation effects are unreliable as they ignore the associated high uncertainty (Rudebusch 1992,1993; Diebold and Senhadji 1996).

\footnotetext{
${ }^{18}$ We use the state-space approach proposed by Morley (2001) to estimate the trend in the U.S. coincident index on the assumption that the proper time series model is $\operatorname{ARIMA}(2,1,2)$. The cyclical component is defined as the difference between the index and its trend.

${ }^{19}$ This is consistent with the underlying theoretical preconception that attributes most of the cyclical instability to exogenous shocks, many of which are supposed to influence the levels of macroeconomic variables in the long run. With monetary shocks believed to have only temporary real effects, the attention here centers on real, especially productivity, shocks. But, as developed elsewhere (Zarnowitz 1992, 1999; Glasner 1997, pp. 557-560), there is much that is doubtful about this approach: the exclusion of any plausible endogenous sources of economic instability; the relative neglect of financial and expectational factors and of sectoral interactions; the uncertain measurement of productivity shocks. (Some of these points have been recognized by real business cycle (RBC) theorists; see King and Rebelo 2000).
} 
Also, note that there is little to be done about the unpredictable shocks, their hypothetical long-term effects, and the stochastic variations in economic activity generally. Hence, countercyclical stabilization policies have very limited scope and promise to those who follow the DS-stochastic trend-RBC approach. This is not necessarily a deficiency of the theory, but it may help explain the interest of many economists in exploring what may be causing business cycles beyond shocks (Fuhrer and Schuh 1998).

Table 2 compares the timing of growth cycles according to different methods of detrending the U.S. coincident index. The Beveridge- Nelson trend deviations lead at three peaks and at one trough in the PAT deviations by significant intervals but show lags, generally short, at most other turns (column 1). They miss only one PAT slowdown, in 1962-64. On average, the timing of the two series is approximately coincident (with means and medians within the \pm 3 months interval).

\subsection{The Local Linear Trend Model}

As noted by James H. Stock in an invited comment on the first draft of this paper prepared for the meeting of The Conference Board Business Cycle Indicators Advisory Committee (March 2, 2000), the theory of optimal linear filtering is very well developed and understood so one can assess the various filters well on a priori grounds for their suitability in the present context. One desirable feature here is to have changing drifts that allow for persistent fluctuations in the mean growth rates. Stock suggests that this may favor a local linear trend model which allows the drift to change. 
This type of structural model is discussed by Harvey $(1989,2000)$ who assumes that a time series, $y_{t}$, is composed of a stochastic trend, $\mu_{t}$, and an irregular term, $\varepsilon_{t}$ as in equation (1) below. ${ }^{20}$ Equations (2) and (3) describe how the slope of the stochastic trend, $\beta_{t}$, is itself a random walk process. The error terms $\varepsilon_{t}, \eta_{t}$, and $\zeta_{t}$ are normally and independently distributed with zero means and variances $\sigma_{\varepsilon}^{2}, \sigma_{\eta}^{2}$, and $\sigma_{\zeta}^{2}$ respectively.

$$
\begin{array}{ll}
y_{t}=\mu_{t}+\varepsilon_{t} & t=1, \ldots, T \\
\mu_{t}=\mu_{t-1}+\beta_{t-1}+\eta_{t} & \\
\beta_{t}=\beta_{t-1}+\zeta_{t} &
\end{array}
$$

Depending on the assumptions about the variances of the error terms, different trends can be obtained this framework. If variances of both $\eta_{t}$ and $\zeta_{t}$ are zero, the model reduces to a deterministic linear trend. Alternatively, if only the variance of $\zeta_{t}$ is zero, the trend is a random walk with drift as in the Beveridge-Nelson decomposition. When the variance of $\eta_{t}$ is fixed at zero and the variance of $\zeta_{t}$ is positive, the resulting local linear trend is an integrated random walk trend or a smooth trend (see Harvey 2000, p 3).

The model with local linear trend can be cast in the state-space form and the Kalman filter can be used to get estimates of the unobserved trend and slope components (see Harvey 1989, ch. 4). Restricting our attention here to a specific set of assumptions

\footnotetext{
${ }^{20}$ Note that no separate cycle component is distinguished here. A cyclical component is modeled explicitly in Harvey 1985, but the empirical applicability of this framework is severely limited, especially for the post- World War II period by the use of annual data only.
} 
without prior testing of their appropriateness, we estimate the model of equations (1)-(3) along these lines to see if it can give good results in terms of growth cycles.

We believe a good trend estimate should be influenced by the cyclical movements in the data but it should also be smooth. This implies that the trend should show only slow slope changes, with small innovations. Arguably, then, the variance of the residuals in the equation for the trend slope should be small, and so we assume $\sigma_{\zeta}^{2}=10^{-9}$ while fixing $\sigma_{\eta}^{2}$ at zero. The estimated value of $\sigma_{\varepsilon}^{2}$ for the natural $\log$ of the U.S. coincident index for $1948-2000$ is 0.0005 . This, it is interesting to note, is very close to the variance of the deviations from PAT, which is 0.00036 , suggesting that the local linear trend may give results similar to the PAT. Indeed, when estimated with the parameter values we selected, the local linear trend is smooth $(\mathrm{MCD}=1)$; its slope changes slowly and is relatively steeper during periods of high average growth rates (Chart 10). Compared with the PAT in Chart 1, this trend doesn't flatten as much during recessions.

The deviations from the local linear trend shown in Chart 11 are smaller and smoother than the deviations from PAT in Chart 2. They dip only slightly and briefly below zero at the end of the 1951-52 and 1979-80 growth cycle contractions, and remain positive throughout during the slowdowns of 1966-67 and 1984-86. Conversely, in the retardations of 1963-64 and 1995, this series consists entirely or almost entirely of negative values. In these respects, the local linear trend deviations resemble the larger Beveridge-Nelson trend deviations (compare Charts 11 and 9). The PAT deviations alternate better between positive and negative values in these periods.

The series of deviations from local linear trend, we have estimated shows timing coincident with that of PAT at most peaks and troughs (there are only eight nonzero 
entries here, and only four of them large; see Table 2, col. 2). This correspondence is much better than that between the Beveridge-Nelson and PAT deviations. It is interesting because this trend does not explicitly take account of the turning points in the data as PAT does.

\subsection{The Hodrick-Prescott Trend}

Let a time series $y_{t}$ be viewed as the sum of a growth (trend) component $g_{t}$ and a cyclical component $c_{t}: y_{t}=g_{t}+c_{t}$ for $t=1, \ldots, T$. The growth component should be smooth, so that the procedure recommended by Hodrick and Prescott (1997) is to minimize

$$
\sum_{t}^{T} c_{t}^{2}+\lambda \sum_{t}^{T}\left[\left(g_{t}-g_{t-1}\right)-\left(g_{t-1}-g_{t-2}\right)\right]^{2}
$$

where the parameter $\lambda$ is positive. The larger $\lambda$, the smoother is the result; if $\lambda$, which penalizes variability in $g_{t}$, is large enough, $g_{t}$ approaches $g_{0}+\beta t$. Hodrick and Prescott favor $\lambda=1,600$ for quarterly data, but show that the numbers change little if $\lambda$ is reduced or increased by a factor of four.

The squared second difference of the trend component, $g_{t}$, which is multiplied by $\lambda$, is a very small term. Even very large changes in $\lambda$, therefore, influence the cyclical component $c_{t}$ only modestly. For annual observations, $\lambda$ values of 400 or 100 have been used, but Baxter and King (1999) argue that 10 gives better results. We are interested in applications to monthly data, and obtain reasonably good results with $\lambda=$ 14,400. As shown in Charts 12 and 13, the H-P trend shows both a considerable smoothness and some cyclical flexibility in this case, while the deviations from trend 
decline into negatives in each downward phase of growth cycles dated according to the PAT (see first curves in each chart). The only exceptions to this one-to-one correspondence occur in 1956 and 1959, when the H-P deviations series falls briefly below zero during apparent growth cycle upswings, and in 1989-90, when it shows an overly strong extra rise during a slowdown. When the outliers are properly considered, the turning points in the H-P and the PAT growth cycles are either identical or very close in time, with but two significant deviations: the peak near the beginning of the sample period and the trough in 1991 (see Table 2, col. 3).

However, it is worth noting that the H-P series has smaller fluctuations and is less smooth than the PAT series (compare Chart 13 first curve with Chart 2). In particular, the H-P cyclical component (with $\lambda=14,400$ ) seems to distort both the sluggish recovery in the early 1990s (by showing an early upswing) and the vigorous boom in the late 1990s (by showing only weak and erratic positive deviations from trend).

As an experiment, we performed a search to locate a value of $\lambda$ that would minimize $d=\sum_{t}^{T}\left(p_{t}-h_{t}\right)^{2} / T$, where $p_{t}$ and $h_{t}$ represent the series of PAT and the H-P trend respectively. With $\lambda=14,400, d=0.45$; when $\lambda$ is increased by increments of 100 , $\mathrm{d}$ reaches a minimum of 0.16 for $\lambda=108,000$. We add the corresponding trend and detrended values to Charts 12 and 13, respectively as second curves. The 7.5 -fold increase in $\lambda$ produces moderate improvements in the new H-P estimate of the "cyclical component." The H-P deviations series for $\lambda=108,000$ has somewhat larger and on the whole, more symmetrical fluctuations than the series for $\lambda=14,400 .{ }^{21}$ The estimate with

\footnotetext{
${ }^{21}$ However, note that in the years 1962-67 the series for $\lambda=108,000$ is less symmetrical around zero than the series for $\lambda=14,400$ (see Chart 13).
} 
larger $\lambda$ is quite similar to the PAT, even in many small details. (For example, the recovery in the early 1990s is now slow in both series; the deviations from trend in the late 1990s are relatively small in both, too, but particularly so in the H-P deviations.) Yet, remarkably, the H-P detrended series are not very smooth, even when $\lambda$ is set as high as 108,000: the MCD is 2 for each of the two variants we have constructed and tested.

\subsection{The Rotemberg Trend}

Rotemberg (1999) proposes a heuristic method of time series decomposition which estimates the value of $\lambda$ given two parameters, $\mathrm{k}$ and $\mathrm{v}$. Using the earlier notation, let $y_{t}=g_{t}+c_{t}$, where $g_{t}$ and $c_{t}$ are trend and cycle components of the time series $y_{t}$, respectively. The parameter $\mathrm{k}$ ensures that the estimated trend minimizes the covariance of two values of the cyclical component, $c_{t}$ and $c_{t+k}$. The parameter v ensures that the trend and cycle components, $g_{t}$ and $c_{t}$, are orthogonal over the horizon of v periods. Specifically, Rotemberg estimates the trend by minimizing

$$
\sum_{t=1+k}^{T} c_{t} * c_{t-k}+\lambda \sum_{t=2}^{T-1}\left[\left(g_{t}-g_{t-1}\right)-\left(g_{t-1}-g_{t-2}\right)\right]^{2}
$$

$\lambda$ is chosen as the lowest parameter value such that the following constraint holds

$$
\sum_{t=k+v}^{T-k-v} c_{t} *\left[\left(g_{t+v}-g_{t}\right)-\left(g_{t}-g_{t-v}\right)\right]=0 .
$$

Rotemberg recommends that $\mathrm{k}$ be set to equal 16 quarters on the admittedly somewhat arbitrary ground that historically NBER business cycle troughs for the U.S. 
have been four years apart on average. (The dispersion around this average is very

large.) With large $\mathrm{k}$, the minimization of (5) results in a trend that is quite smooth and not very sensitive to either the cyclical movements of the series nor the choice of v. With low $\mathrm{k}$ - a fortiori, with zero $\mathrm{k}$, which is the case in the H-P trend - the effects are opposite. Rotemberg chooses $\mathrm{v}$ to equal five quarters.

Chart 14 shows what happens when this procedure $(\mathrm{k}=48$ months and $\mathrm{v}=15$ months) is applied to the U.S. coincident index between January 1948 and December 2000 while Chart 15 shows the deviations from this trend. The trend in Chart 14 is exceedingly smooth, as the estimate of $\lambda$ is equal to $4,335,498$ ! (MCD is, of course, one.) As expected, the method produces a trend that is rising persistently, with few slope changes. Still Rotemberg's trend decelerates slightly in late 1960s, early 1980s and early 1990s, accelerates slightly in between, notably in the long expansions of the 1960s and the 1990s. So there is some mutual dependence of trend and cycles, but it is minimized.

The deviations in trend shown in Chart 15 track the growth cycle downturns shown by the shaded areas according to PAT fairly well much of the time and much better during recessions than during the other slowdowns. However, these deviations are not very symmetric around zero, their amplitudes vary widely, and the trend is probably not high enough at the end of the sample after 1998 (a shortcoming noted by Rotemberg). The growth cycles are reduced strongly (those in 1951-52, 1963-64, 1966-67, 1984-86, and 1995 are almost eliminated) so that the general appearance of the fluctuations in this chart tracks business cycles rather than growth cycles. Table 2 col. 4 shows several close correspondences but also large discrepancies between the timing of this trend and that of PAT. 


\subsection{Band-Pass Filters}

Baxter-King (1999) propose a band-pass filter that isolates the components of the time series with fluctuations between six and 32 quarters and removes the components of higher and lower frequencies as "noncyclical”. They refer to Burns and Mitchell's definition of business cycles in support of this choice. But NBER research always required that business cycles involve absolute declines (contractions) in economic activity, whereas Baxter and King (1999) like most others attempting statistical trendcycle decompositions make no distinction between business cycles and growth cycles. Hence, to begin with, it must again be noted that they all obtain estimates of growth cycles, not business cycles. Second, Burns and Mitchell define business cycles as ranging up to 10 or 12 (not 8 ) years, and Table 1 col. 12 , suggests that cycles exceeding eight years in duration may no longer be so rare. In contrast, growth cycles lasted 2-6 years in the recent era (Table 1, col. 6). Finally, NBER researchers would always determine cyclical timing and other properties of time series in seasonally adjusted but otherwise unsmoothed time series, using moving averages cautiously for guidance only.

The band-pass filtering approach decomposes series into trend, cycle, and irregular components corresponding respectively to the low, intermediate, and high frequency parts of the spectrum (Stock and Watson 1998). As noted by Stock in his March 2000 comment (see note 8), the bandpass method filters out all fluctuations at both low and high frequencies that are considered "noncyclical". The resulting series are therefore relatively smooth, which makes for nice graphs, often with well-articulated turning points. But the latter may well be misdated if the short-period variations of the indicators around their peaks and troughs are not taken into account properly. Hence, the 
elimination of high frequency changes from data may affect the results adversely. Furthermore, it is doubtful that one can precisely identify the exclusively "cyclical" frequencies and assume that the resulting band-pass filter remains valid and constant over time. In some very long phases (e.g., the contraction of the 1930s, the expansions of the 1960s and the 1990s), the relevant frequency mix may be rather different from that applying to some very short phases (e.g., the back-to-back recessions separated by the incomplete recovery in the early 1980s). Thus, much flexibility is needed in reconciling reasonable trend estimates with both unusually long and unusually short cyclical movements. On that, the PAT method is probably at a significant advantage vis-à-vis the H-P and band-pass filtering methods.

We experimented with a wide range of band-pass filters so as to accommodate the wide range of growth cycles of actual experience. Generally, the narrower the band, the more numerous and the smaller are the fluctuations in the deviations from trend. The evidence suggests that narrow bands are inferior to wide bands in that they produce too many estimated growth cycles. For example, using the band-pass filter with a frequency range of nine to 50 months one gets 18 growth cycles; using a band of 12 to 50 months, one gets 19 cycles.

Chart 16 shows the trend and Chart 17 shows the deviations from trend based on a band-pass filter of wide range ( 9 to 96 months). The trend is what is left after the cyclical component and the irregular component (less than 9 months) are subtracted from the seasonally adjusted U.S. coincident index. Again, the shaded areas on the chart indicate the growth cycle slowdowns according to the PAT. A comparison of Charts 2 and 17 suggests that the band-pass filter for the selected frequency range produced almost a 
smoothed version of the PAT deviations series. The only blemishes we can find here is that the declines in 1951-52 and 1962-63 are underrepresented (the former is limited to positives, the latter to negatives; see Chart 17).

Table 2 col. 5 compares the peak and trough dates in the cyclical component derived by using the band-pass filter with those in the deviations from PAT. The timing of the two series is virtually identical; evidently, smoothing has not distorted it in this case.

\section{Conclusion}

A trend denotes a long-run tendency in economic time series, for example, an upward inclination reflecting real growth or cost (price) inflation. There is so much variability in intermediate and short run components of many series - cyclical, seasonal, irregular - that it is useful to define trend by contrast as relatively smooth, that is changing rather slowly, without sudden disturbances that are difficult to explain. The smoothest are the linear trends, yet linear trends are hard to find, for several good reasons. Economies grow through cycles of expansions and contractions that vary widely in amplitude and duration. Long expansions (contractions) can tilt growth trends upward (downward). So can sequences of such phases or upswings and downswings of economic "long waves," to the extent they exist. Great technological innovations speed up growth temporarily, disruptions of supply or demand in times of war, civil conflict or industrial dispute deter growth temporarily. Monetary and exchange regimes differ, periods of inflation and deflation have historically alternated. Thus trends may be smooth but they vary and change. 
We have looked at different methods of time series decomposition from the viewpoint of how best separate trends and growth cycles, i.e. fluctuations in data adjusted for both long-term and seasonal movements. Smoothness in trends is desirable, linearity over short periods may be, linearity over long periods is not. The most difficult problem for time-series decomposition in the present context arises because trends and business cycles interact. Just as a long phase of depressed or stagnating business conditions can lower the long trend so a long period of maintained high growth can reduce cyclical instability by replacing recessions with slowdowns. So a nonlinear or at least a local or piecewise linear trend, which allow for the trend-cycle interaction, is apt to do a better job than a linear trend.

The Phase Average Trend (PAT) program developed at the NBER (Boschan and Ebanks 1978) exemplifies such a trend, with the explicit purpose of growth cycle measurement. PAT addresses the task directly by using preliminary growth cycle turning points and it serves the purpose on hand well. This is revealed by a close examination of cyclical movements since 1948 in two principal measures of U.S. aggregate economic activity - the monthly coincident index and the quarterly real GDP. Growth cycles appear clearly in both the deviations from trends and the smoothed growth rates for the series. They complement well the business cycles as measured in the corresponding data on levels of CI and real GDP.

We have compared the patterns, timing, amplitudes, and smoothness of several estimates of U.S. growth cycles in the post World War II period obtained by using different methods of detrending the monthly coincident index 1948-2000. Log-linear trends are clearly inferior for our purposes. The stochastic Beveridge-Nelson trend is 
much better but it includes too much of cyclical fluctuations and the deviations from it often lack the proper patterns and timing. The local linear trend of Harvey leaves deviation cycles that are substantially smaller than those produced by PAT, but the two sets are closer in timing. The Hodrick-Prescott approach is flexible, and with very high $\lambda$ it produces growth cycles quite similar to PAT but it falls short on smoothness. Rotemberg's heuristic trend is very smooth, but the deviations from it vary widely in amplitude, miss some growth cycles, and are not as symmetric as the deviations from PAT and some other trends. The band-pass filter works quite well for wide frequency ranges (much worse for narrow ranges) and produces very smooth growth cycles very similar to those of PAT. In general, it is reassuring that the results of PAT for the United States show great similarity to the results obtained with the more modern H-P and bandpass filtering methods, but in matters of detail PAT is often superior. 


\section{References}

Baxter, M. and R. G. King. (1999), Measuring Business Cycles: Approximate Band-Pass Filters for Economic Time Series, Review of Economics and Statistics, Vol. 81(4), 57593.

Beveridge, S. and C. R. Nelson. (1981), A New Approach to Decomposition of Economic Time Series into Permanent and Transitory Components with Particular Attention to Measurement of the "Business Cycle," Journal of Monetary Economics, Vol. 7, 151-74.

Boschan, C. and W. W. Ebanks. (1978), The Phase-Average Trend: A New Way of Measuring Growth, in 1978 Proceedings of the Business and Economic Statistics Section, American Statistical Association, Washington, D.C.

Bry, G. and C. Boschan. (1971), Cyclical Analysis of Time Series: Selected Procedures and Computer Programs, National Bureau of Economic Research, New York.

Burns, A. F. (1934), Production trends in the U.S. economy since 1870. National Bureau of Economic Research, New York.

Burns, A. F., and W. C. Mitchell. (1946), Measuring Business Cycles, National Bureau of Economic Research, New York.

Burnside, Craig. (1998), Detrending and Business Cycle Facts: A Comment, Journal of Monetary Economics, 41(3), 512-32.

Canova, Fabio. (1998a), Detrending and Business Cycle Facts, Journal of Monetary Economics, 41(3), 475-512.

Canova, Fabio. (1998b), Detrending and Business Cycle Facts: A User's Guide, Journal of Monetary Economics, 41(3), 533-40.

Canova, Fabio. (1999), Does Detrending Matter for the Determination of the Reference Cycle and the Selection of Turning Points? Economic Journal, 109(452), 126-50.

Diebold, F. X. and A.S. Senhadji. (1996), Deterministic vs. Stochastic Trend in U.S. GNP, Yet Again, National Bureau of Economic Research Working Paper No. 5481.

Diebold, F. X. and G. D. Rudebusch. (1999), Business Cycles: Durations, Dynamics, and Forecasting, Princeton University Press, Princeton.

Friedman, M. and A. J. Schwartz. (1963), Money and Business Cycles, Review of Economics and Statistics, Vol. 45, suppl., 32-64. 
Fuhrer, J. C. and Schuh, S., eds. (1998), Beyond Shocks: What Causes Business Cycles?, Conference Series, no. 42., Federal Reserve Bank of Boston, Boston.

Glasner, D. ed. (1997), Business Cycles and Depressions: An Encyclopedia, Garland Reference Library of Social Sciences, Vol. 505, Garland Publishing, Inc., New York and London.

Harding D., and A.R. Pagan, Forthcoming, "Dissecting the cycle: a methodological investigation", Journal of Monetary Economics.

Harvey, A. C. (1989), Forecasting, Structural Time Series Models and the Kalman Filter, Cambridge University Press, Cambridge, New York and Melbourne.

Harvey, A. C. (1985), Trends and Cycles in Macroeconomic Time Series, Journal of Business and Economic Statistics, Vol. 3(3), 216-227.

Harvey, A. C. (2000), Trend Analysis, University of Cambridge, Faculty of Economics and Politics, Manuscript.

Hodrick, R. J. and E. C. Prescott. (1997), Postwar U.S. Business Cycles: An Empirical Investigation, Journal of Money Credit and Banking, Vol. 29(1), 1-16.

King, R.G., C. I. Plosser, J. H. Stock, and M.W. Watson. (1991), Stochastic Trends and Economic Fluctuations, American Economic Review, Vol. 81, 819-840.

King, R. G. and S. T. Rebelo. (2000), Resuscitating Real Business Cycles, National Bureau of Economic Research Working Paper No. W7534.

Kim, C. J. and C. R. Nelson. (1998), Business Cycle Turning Points, a New Coincident Index, and Tests of Duration Dependence Based on a Dynamic Factor Model with Regime Switching, Review of Economics and Statistics; Vol. 80(2), 188-201.

Klein, P. A. and G. H. Moore. (1985), Monitoring Growth Cycles in Market-Oriented Countries: Developing and Using International Economic Indicators, Ballinger for NBER, Cambridge, Mass.

Kuznets, S. (1930), Secular movements in production and prices, Houghton Mifflin, Boston.

Macaulay, F. C. (1931), The smoothing of time series, National Bureau of Economic Research, New York.

Macaulay, F. C. (1938), The movements of interest rates, bond yields, and stock prices in the United States since 1856, National Bureau of Economic Research, New York. 
Mintz, I. (1969), Dating Postwar Business Cycles: Methods and Their Application to Western Germany, 1950-1967, Occasional Paper No. 107, National Bureau of Economic Research, New York.

Mintz, I. (1972), Dating American Growth Cycles, in Zarnowitz, V., ed., The Business Cycle Today, National Bureau of Economic Research, New York.

Mitchell, W.C. (1951), What happens during business cycles: A progress report, National Bureau of Economic Research, New York.

Moore, G. H. and V. Zarnowitz. (1986), The Development and Role of the National Bureau of Economic Research" Business Cycle Chronologies, in: Gordon, R. A., ed., The American Business Cycle: Continuity and Change, University of Chicago Press for NBER, Chicago.

Morley, J. C. (2001), A State-Space Approach to Calculating the Beveridge-Nelson Decomposition, Manuscript, Washington University.

Nelson C. R. and C. I. Plosser. (1982), Trends and Random Walks in Marcoeconomic Time Series: Some Evidence and Implications, Journal of Monetary Economics, Vol. 10, 139-62.

Rotemberg, J. J. (1999), A Heuristic Method for Extracting Smooth Trends from Economic Time Series, National Bureau of Economic Research Working Paper No. 7439.

Rudebusch, G. D. (1992), Trends and Random Walks in Macroeconomic Time Series: A Re-examination, International Economic Review, Vol. 33(3), 661-80.

Rudebusch, G. D. (1993), The Uncertain Unit Root in Real GNP, American Economic Review, Vol. 83(1), 264-72.

Shishkin, J., A. M. Young, and J. C. Musgrave. (1965), The X-11 variant of the census method II seasonal adjustment, Bureau of the Census Technical Paper 15, U.S. Government Printing Office, Washington D.C.

Stock, J. H. (2000), Comment prepared for the meeting of The Conference Board Advisory Committee.

Stock, J. H. and M. W. Watson (1998), Business Cycle Fluctuations in U.S. Macroeconomic Time Series, NBER Working Paper 6528, April.

Thorp, W.L. (1926), Business Annals, National Bureau of Economic Research, New York. 
Watson, M. (1986), Univariate Detrending Methods with Stochastic Trends, Journal of Monetary Economics, Vol. 18(1), 49-75.

Zarnowitz, V. ed. (1972), The Business Cycle Today, National Bureau of Economic Research, New York.

Zarnowitz, V. and G. H. Moore. (1982), Sequential signals of recession and recovery, Journal of Business, Vol. 55, 57-85.

Zarnowitz, V. (1992), Business Cycles: Theory, History, Indicators, and Forecasting, The University of Chicago Press, Chicago.

Zarnowitz, V. (2000), The 'Old' and the 'New' in the U.S. Economic Expansion, The Economic Outlook for 2001, Forty-eighth Annual Conference on the Economic Outlook, The University of Michigan-Ann Arbor. 
Chart 1: U.S. Coincident Index and Phase Average Trend Monthly, 1948-2000*

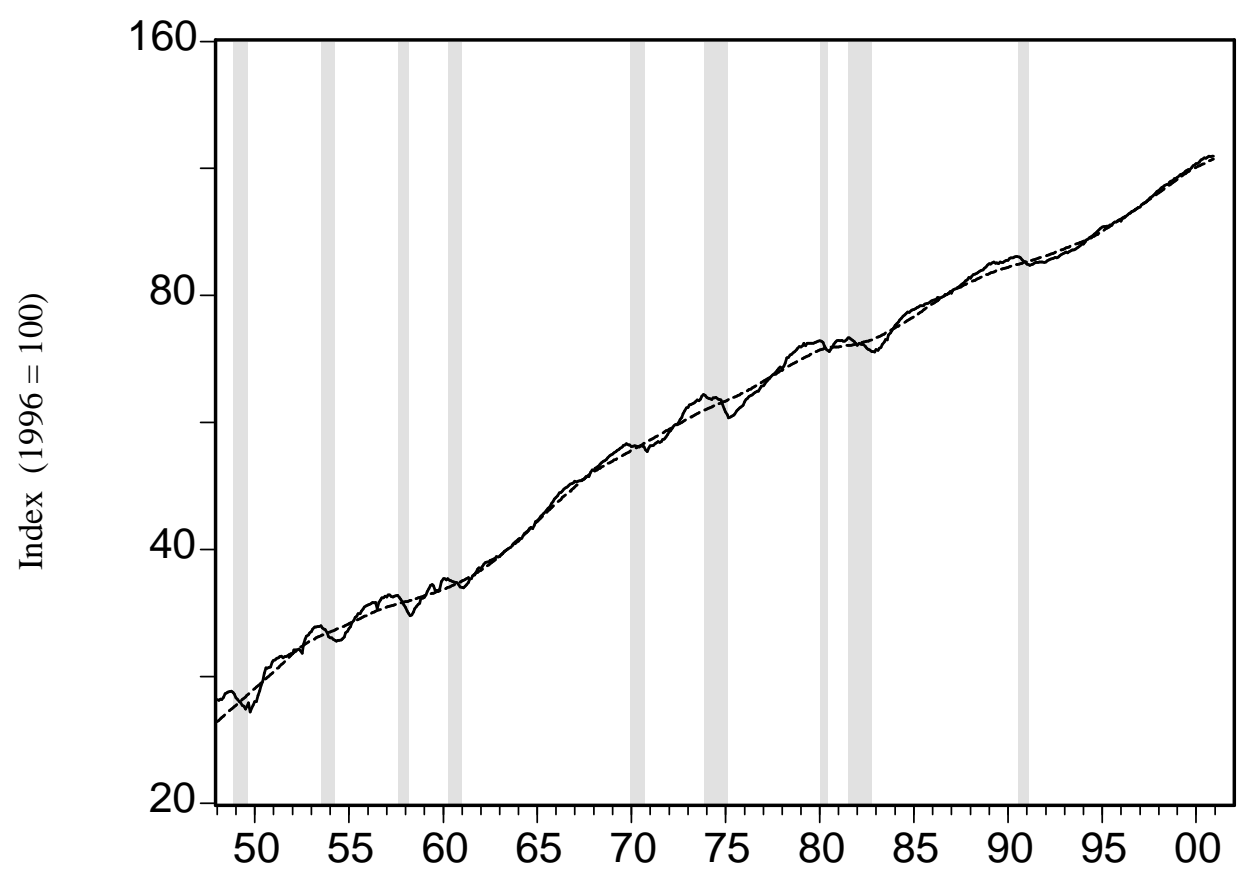

* Shaded areas represent business cycle recessions according to the NBER chronology

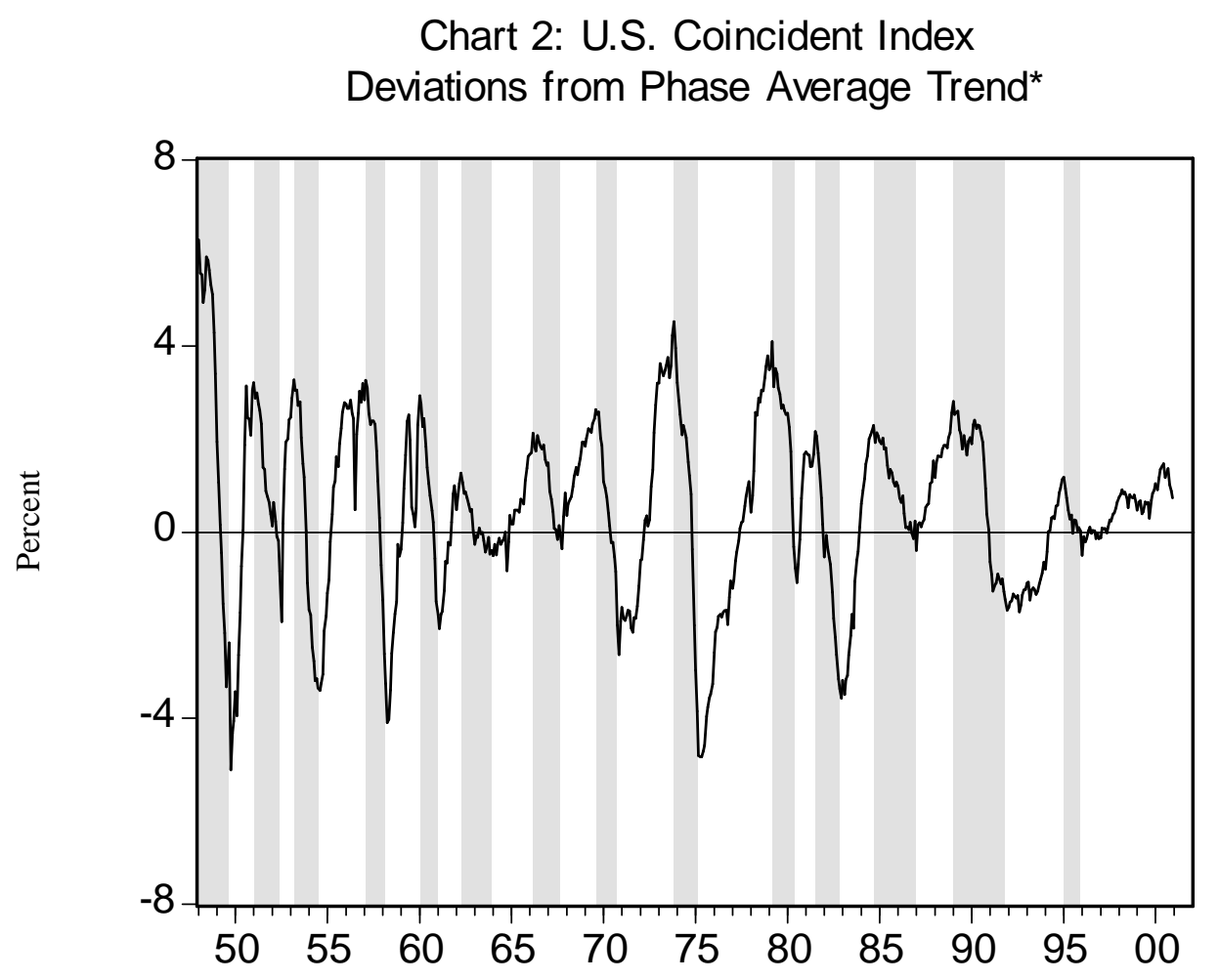

* Shaded areas represent growth cycle recessions based on the U.S. Coincident Index 


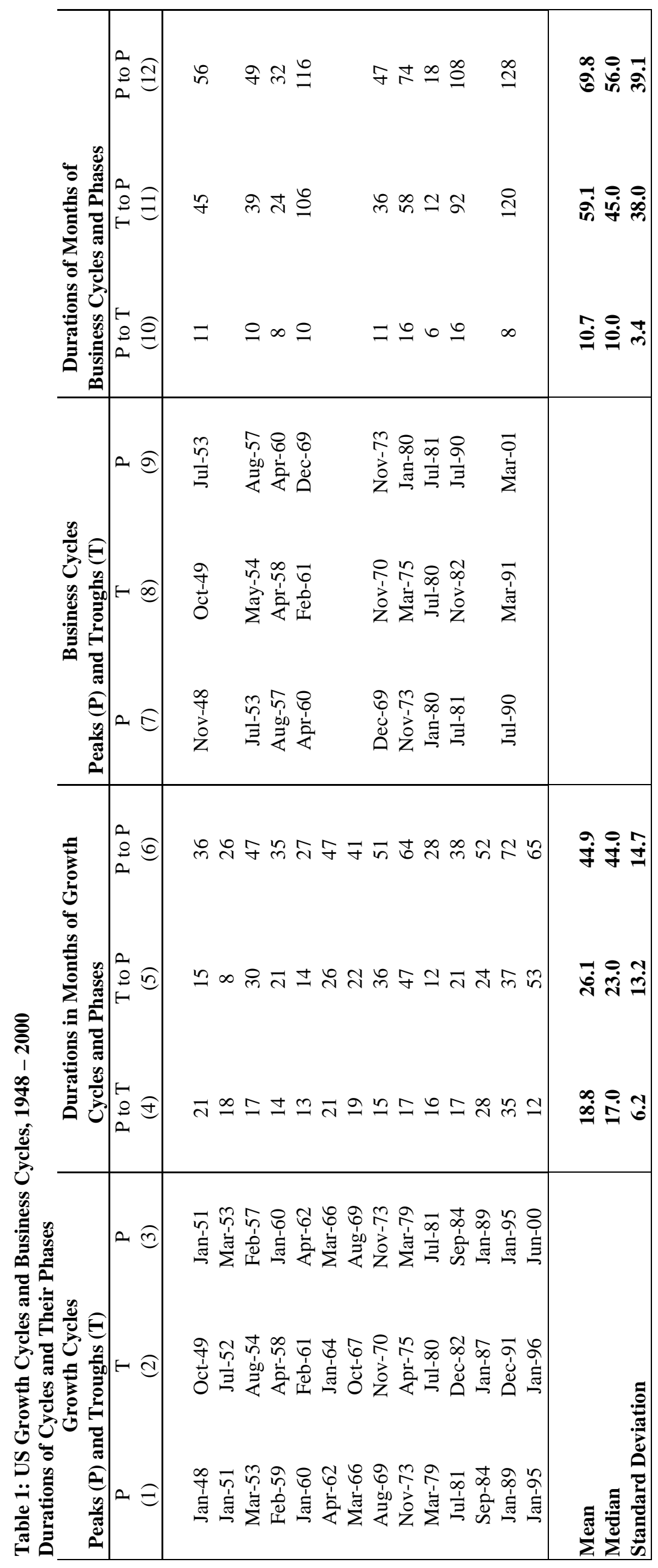


Chart 3: U.S. Real GDP and Phase Average Trend Quarterly, 1947-2000*

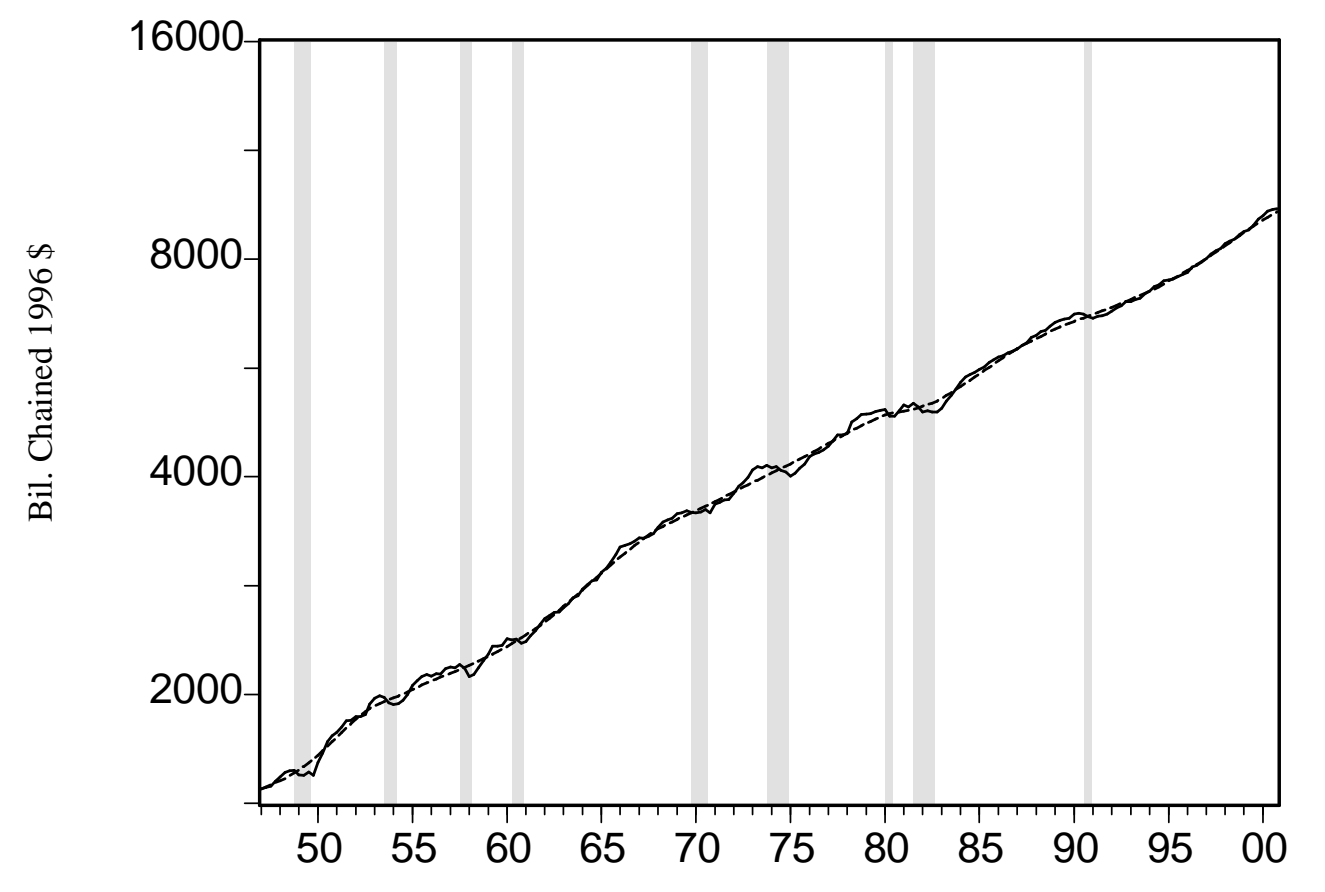

* Shaded areas representbusiness cycle recessions according to the NBER chronology

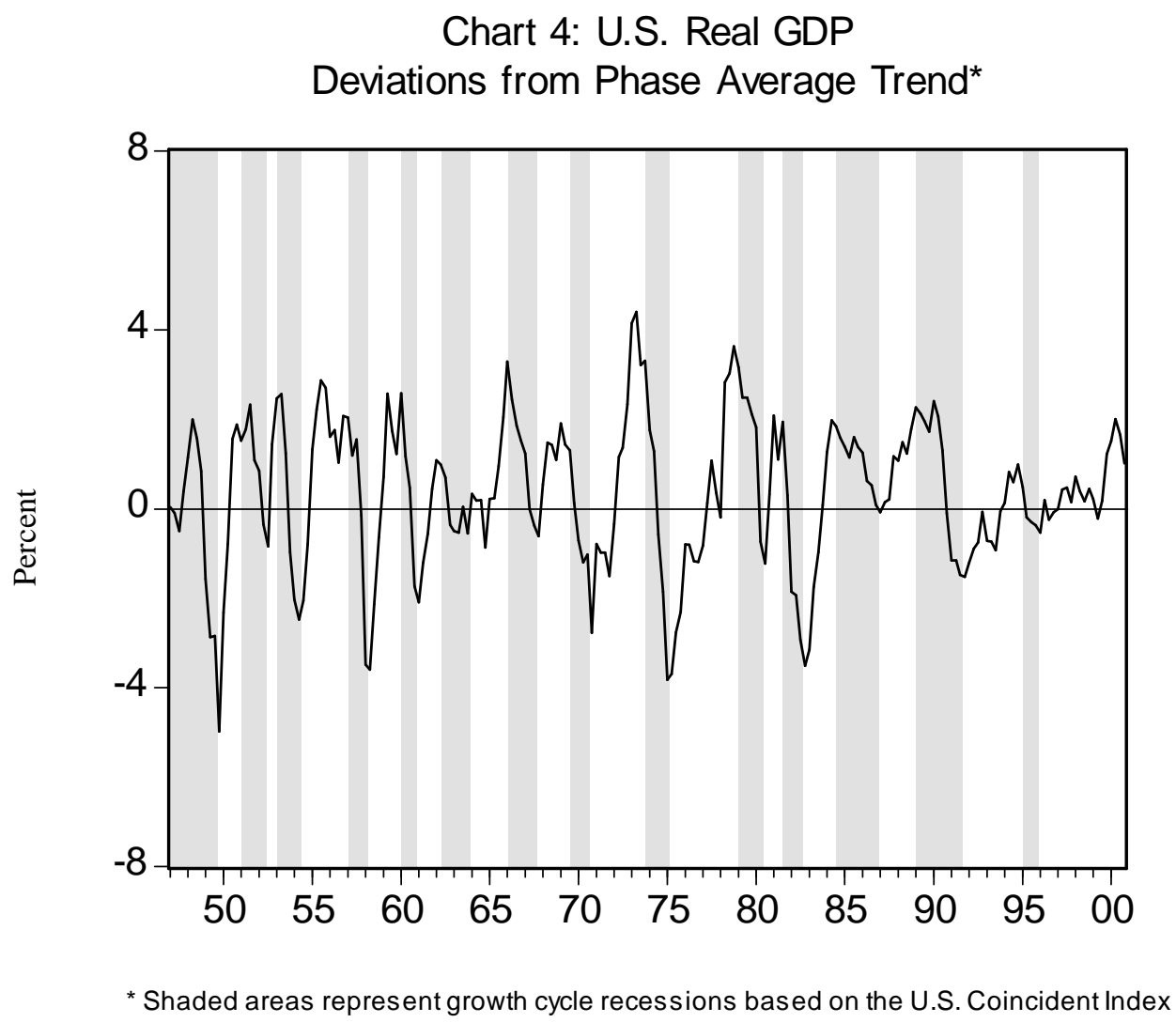


Table 2: Turning Points in Deviations from PAT and in Deviations from Six Different Trend

Estimates, U.S. Coincident Index (1948-2000)

\begin{tabular}{|c|c|c|c|c|c|c|}
\hline \multirow[b]{2}{*}{ PAT } & \multicolumn{6}{|c|}{ Leads(-) or Lags(+) Relative to Peaks in Deviations from PAT } \\
\hline & $\begin{array}{l}\text { Beveridge- } \\
\text { Nelson }\end{array}$ & $\begin{array}{l}\text { Local } \\
\text { Linear }\end{array}$ & $\begin{array}{l}\text { Hodrick- } \\
\text { Prescott } \\
(\lambda=\mathbf{1 4 , 4 0 0 )}\end{array}$ & $\begin{array}{l}\text { Hodrick- } \\
\text { Prescott } \\
(\lambda=\mathbf{1 0 8 , 0 0 0})\end{array}$ & Rotemberg & Band-pass \\
\hline & (1) & (2) & (3) & (4) & (5) & (6) \\
\hline Jan-48 & miss & 6 & 7 & 7 & 6 & 6 \\
\hline Jan-51 & 6 & 0 & 0 & 0 & $\operatorname{miss}^{\mathrm{c}}$ & 0 \\
\hline Mar-53 & 3 & 0 & 0 & 0 & 0 & 0 \\
\hline Feb-57 & -7 & -2 & 0 & 0 & -2 & -2 \\
\hline Jan-60 & 4 & 0 & 0 & 0 & -7 & 0 \\
\hline Apr-62 & $\operatorname{miss}^{\mathrm{a}}$ & 0 & 0 & 0 & 0 & 0 \\
\hline Mar-66 & 2 & 3 & 0 & 0 & 7 & 0 \\
\hline Aug-69 & -7 & 0 & 2 & 0 & 0 & 0 \\
\hline Nov-73 & -7 & 0 & 0 & 0 & 0 & 0 \\
\hline Mar-79 & 1 & 0 & 0 & 0 & 0 & 0 \\
\hline Jul-81 & -3 & -7 & 0 & -7 & $\operatorname{miss}^{\mathrm{d}}$ & 0 \\
\hline Sep-84 & 1 & 6 & 0 & 0 & $\operatorname{miss}^{\mathrm{d}}$ & 0 \\
\hline Jan-89 & 1 & 0 & 0 & 0 & 0 & 0 \\
\hline Jan-95 & 3 & 0 & 0 & 0 & $\operatorname{miss}^{\mathrm{d}}$ & 0 \\
\hline Jun-00 & -18 & 3 & -2 & -2 & 0 & 0 \\
\hline Mean: & -1.62 & 0.60 & 0.47 & -0.13 & 0.36 & 0.27 \\
\hline Median: & 1.00 & 0.00 & 0.00 & 0.00 & 0.00 & 0.00 \\
\hline Std. Dev. & 6.60 & 3.14 & 1.96 & 2.70 & 3.70 & 1.67 \\
\hline
\end{tabular}

\begin{tabular}{|c|c|c|c|c|c|c|}
\hline \multirow[b]{2}{*}{ PAT } & \multicolumn{6}{|c|}{ Leads(-) or Lags(+) Relative to Troughs in Deviations from PAT } \\
\hline & $\begin{array}{l}\text { Beveridge- } \\
\text { Nelson }\end{array}$ & $\begin{array}{l}\text { Local } \\
\text { Linear }\end{array}$ & $\begin{array}{l}\text { Hodrick- } \\
\text { Prescott } \\
(\lambda=\mathbf{1 4 , 4 0 0})\end{array}$ & $\begin{array}{l}\text { Hodrick- } \\
\text { Prescott } \\
(\lambda=108,000)\end{array}$ & Rotemberg & Band-pass \\
\hline Oct-49 & 3 & 0 & 0 & 0 & 0 & 0 \\
\hline Jul-52 & 1 & 0 & 0 & 0 & $\operatorname{miss}^{\mathrm{c}}$ & 0 \\
\hline Aug-54 & 3 & 0 & 0 & 0 & 0 & 0 \\
\hline Apr-58 & 3 & 0 & 0 & 0 & 1 & 0 \\
\hline Feb-61 & 3 & 0 & 0 & 0 & 0 & 0 \\
\hline Jan-64 & $\operatorname{miss}^{\mathrm{a}}$ & -12 & $0^{\mathrm{b}}$ & 0 & -12 & 0 \\
\hline Oct-67 & 1 & 0 & 0 & 0 & 0 & 0 \\
\hline Nov-70 & 2 & 0 & $0^{\mathrm{b}}$ & 0 & 9 & 9 \\
\hline Apr-75 & 4 & 1 & -1 & 0 & 1 & 1 \\
\hline Jul-80 & 3 & 0 & 0 & 0 & $\operatorname{miss}^{\mathrm{d}}$ & 0 \\
\hline Dec-82 & 1 & 0 & 0 & 0 & 0 & 0 \\
\hline Jan-87 & 1 & -7 & 0 & 0 & $\operatorname{miss}^{\mathrm{d}}$ & 0 \\
\hline Dec-91 & -6 & 0 & -9 & 0 & $\operatorname{miss}^{\mathrm{d}}$ & 0 \\
\hline Jan-96 & 1 & 0 & 0 & 0 & $\operatorname{miss}^{\mathrm{d}}$ & 0 \\
\hline Mean: & 1.54 & -1.29 & 0.57 & 0.00 & -0.11 & 0.71 \\
\hline Median: & 2.00 & 0.00 & 0.00 & 0.00 & 0.00 & 0.00 \\
\hline Std. Dev: & 2.50 & 3.63 & 4.29 & 0.00 & 5.33 & 2.40 \\
\hline All & & & & & & \\
\hline Mean: & -0.04 & -0.31 & 0.52 & -0.07 & 0.15 & 0.48 \\
\hline Median: & 1.00 & 0.00 & 0.00 & 0.00 & 0.00 & 0.00 \\
\hline Std. Dev: & 5.15 & 3.45 & 3.24 & 1.91 & 4.38 & 2.03 \\
\hline
\end{tabular}

Note: The turning points in the series are selected by the Bry-Boschan algorithm, except where noted.

${ }^{a}$ The early 1963 decline in the B-N series is too short and too small to qualify and has not been accepted by the algorithm (see Chart 9).

${ }^{b}$ The algorithm selected dates lagging the PAT dates by 9 months in both these cases, but we overruled these choices by considering outliers (which are identical in the PAT and H-P series).

${ }^{C}$ The early 1951 decline in the Rotemberg series is too short and too small to qualify and has not been accepted by the algorithm (see Chart15).

d The Rotemberg series shows only a very short, though sharp, increase in 1980; it skips the 1984-86 slowdown; and its decline in early 1995 is too short and too small to qualify (see Chart 15). 


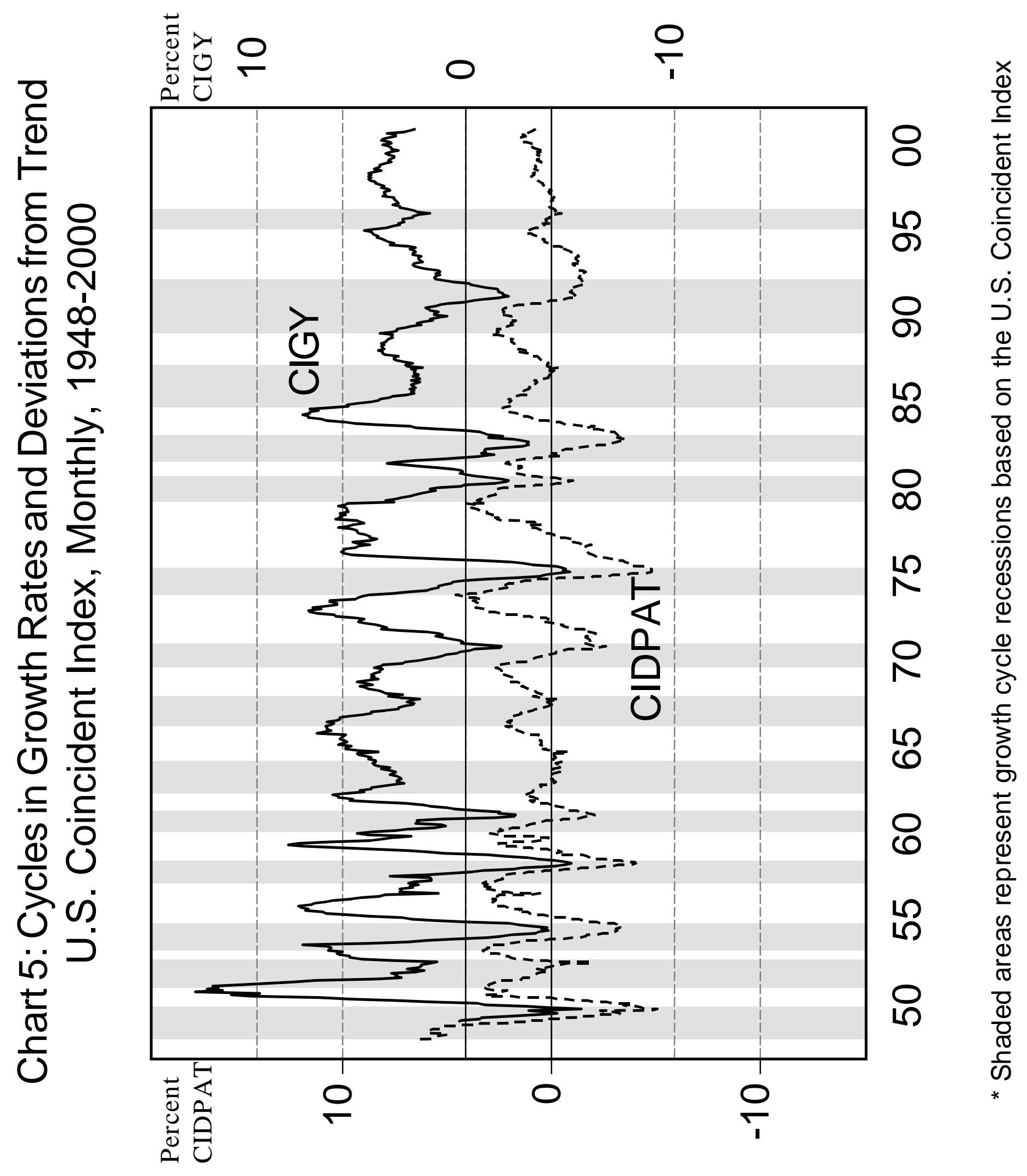




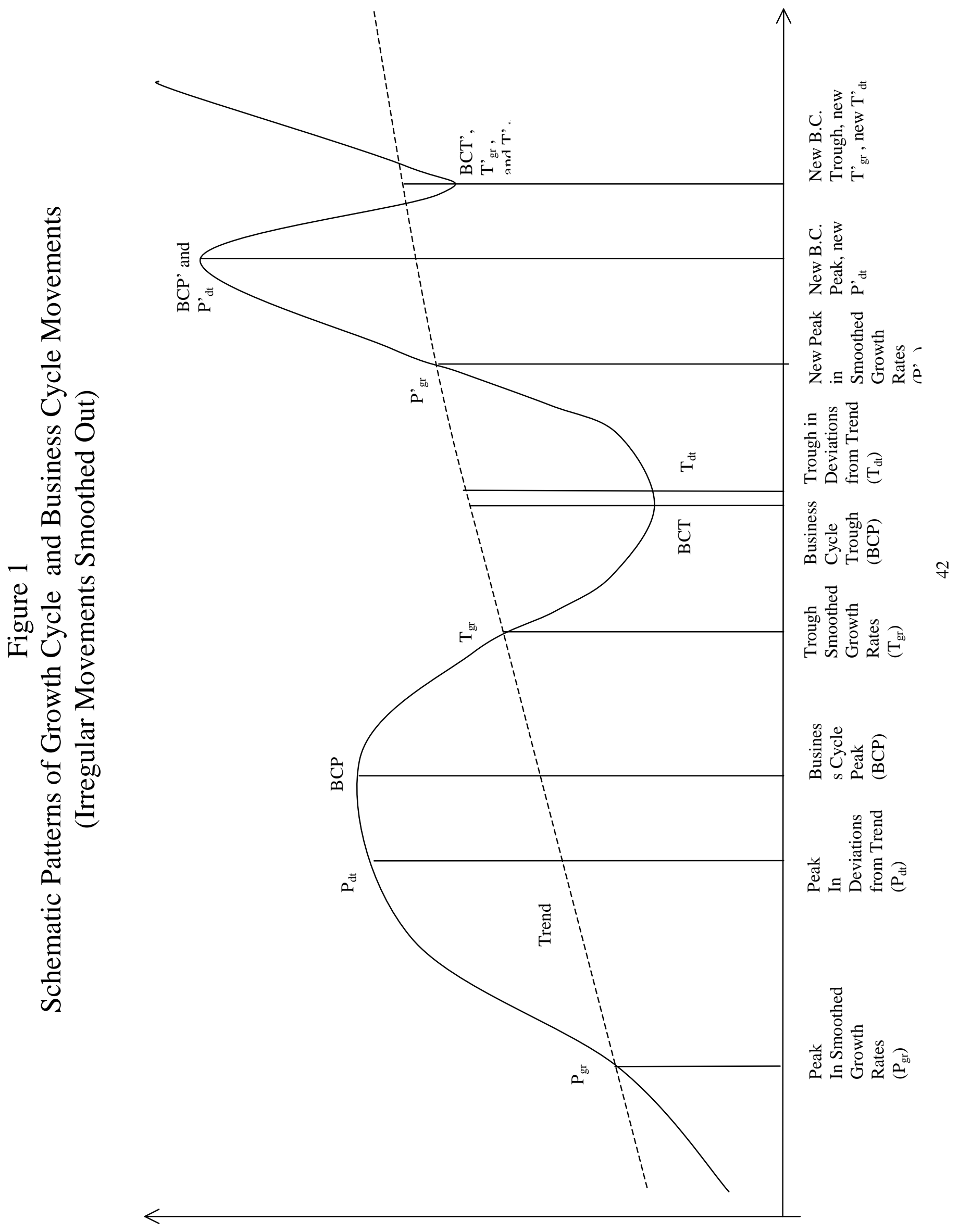


Chart 6: U.S. Real GDP and Its Log-Linear Trend Quarterly, 1947-2000*

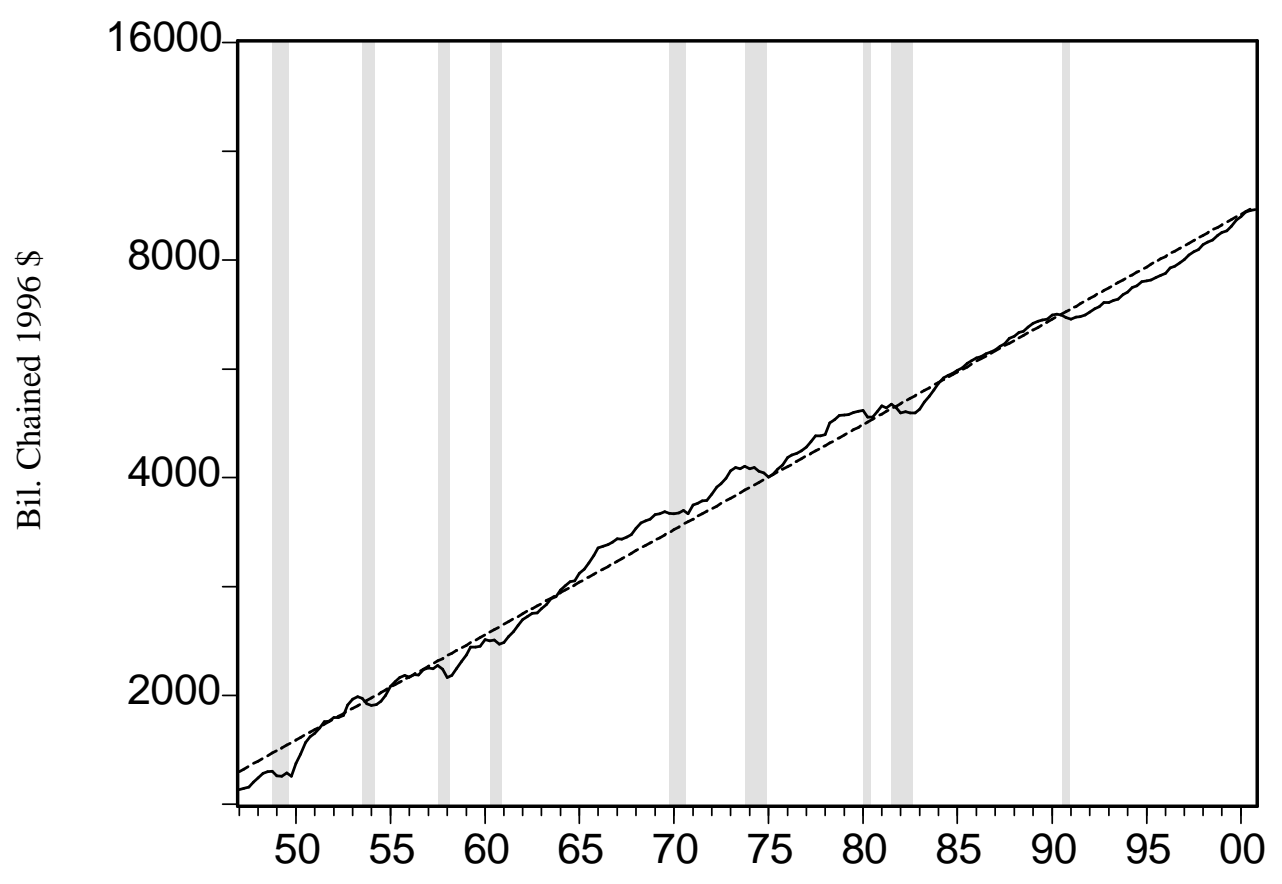

* Shaded areas representbusiness cycle recessions according to the NBER chronology

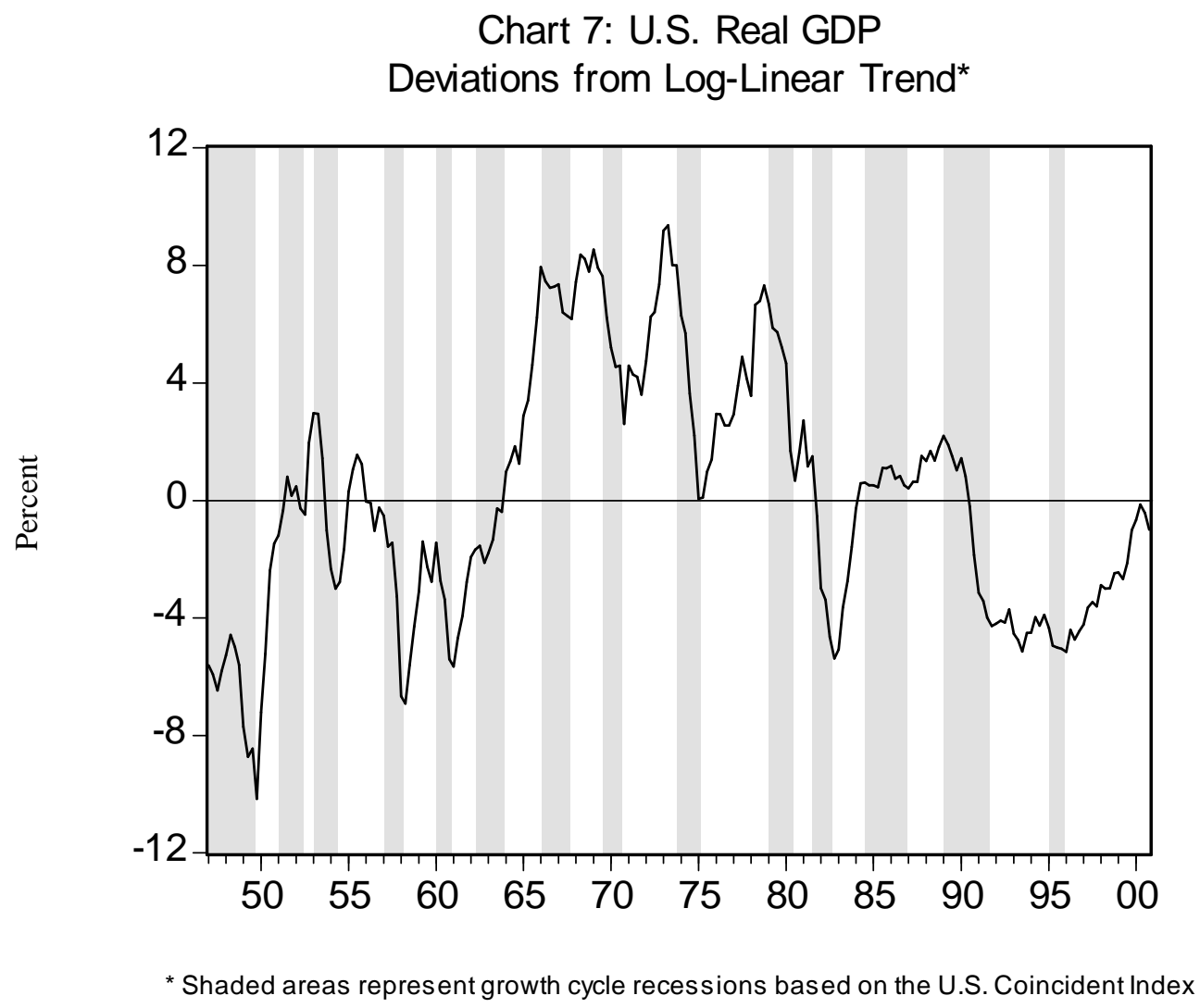


Chart 8: U.S. Coincident Index and Beveridge-Nelson Trend Monthly, 1948-2000*

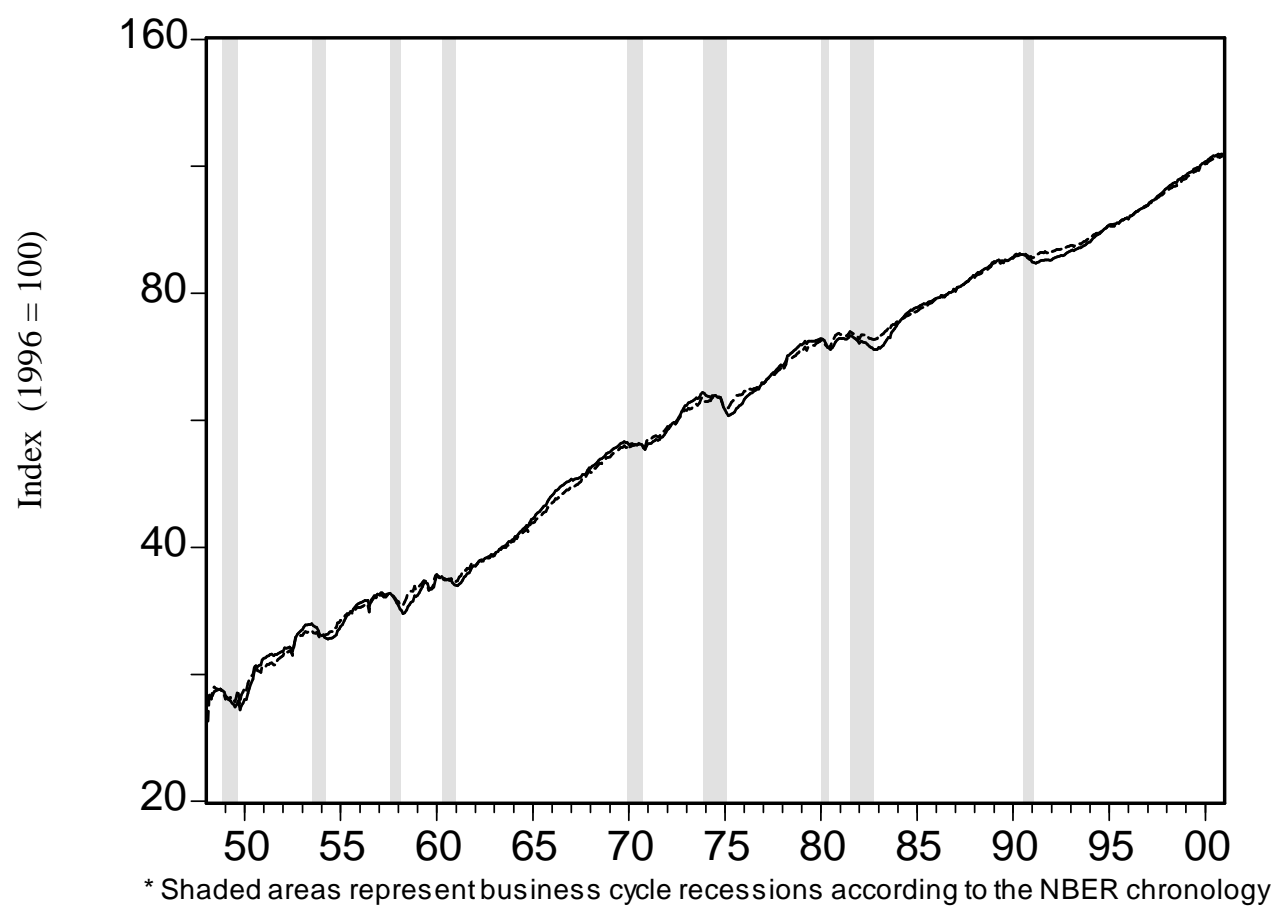

Chart 9: U.S. Coincident Index

Beveridge-Nelson Cycle*

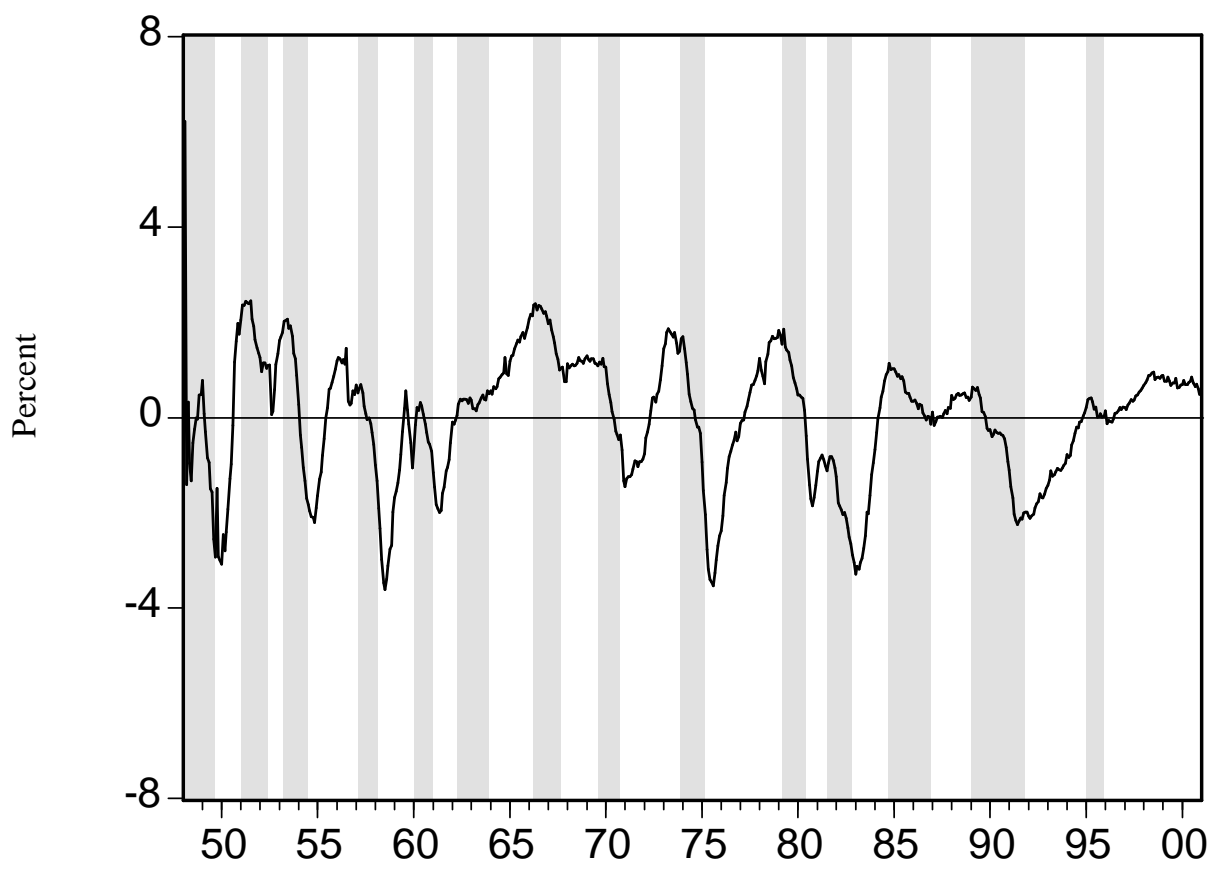

* Shaded areas represent growth cycle recessions based on the U.S. Coincident Index 

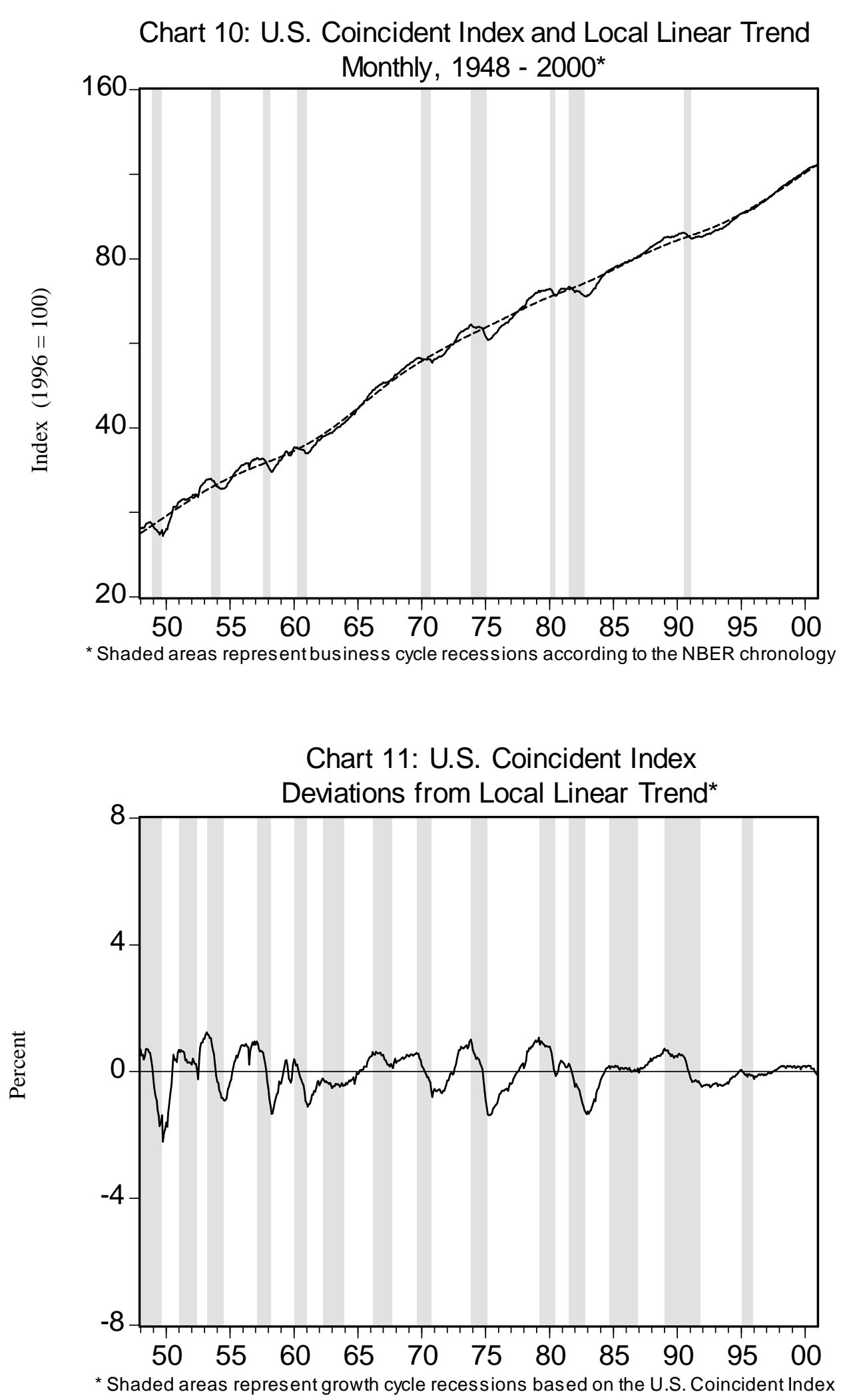
Chart 12: U.S. Coincident Index and Hodrick-Prescott Trend Monthly, 1948-2000*

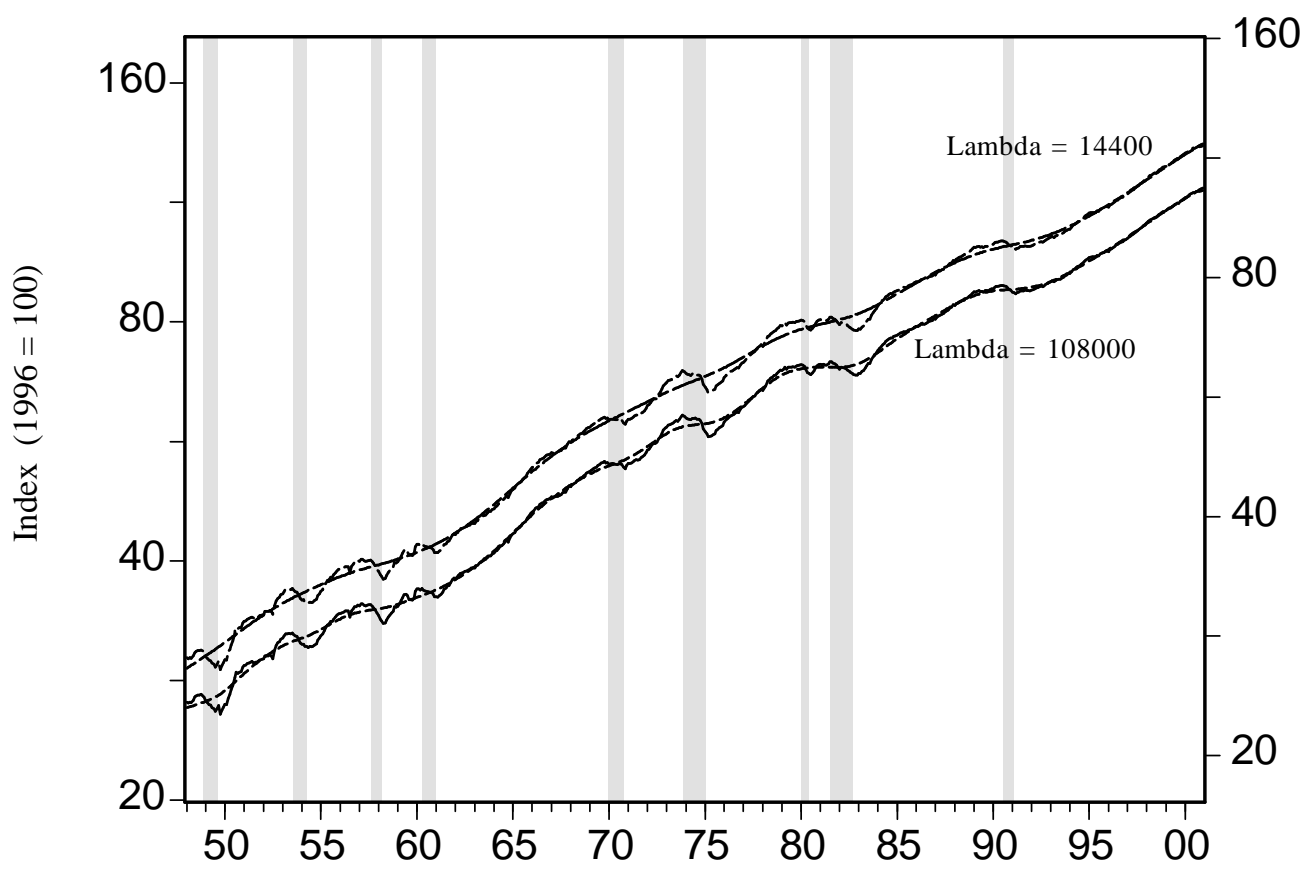

* Shaded areas representbusiness cycle recessions according to the NBER chronology

Chart 13: U.S. Coincident Index Deviations from Hodrick-Prescott Trend*

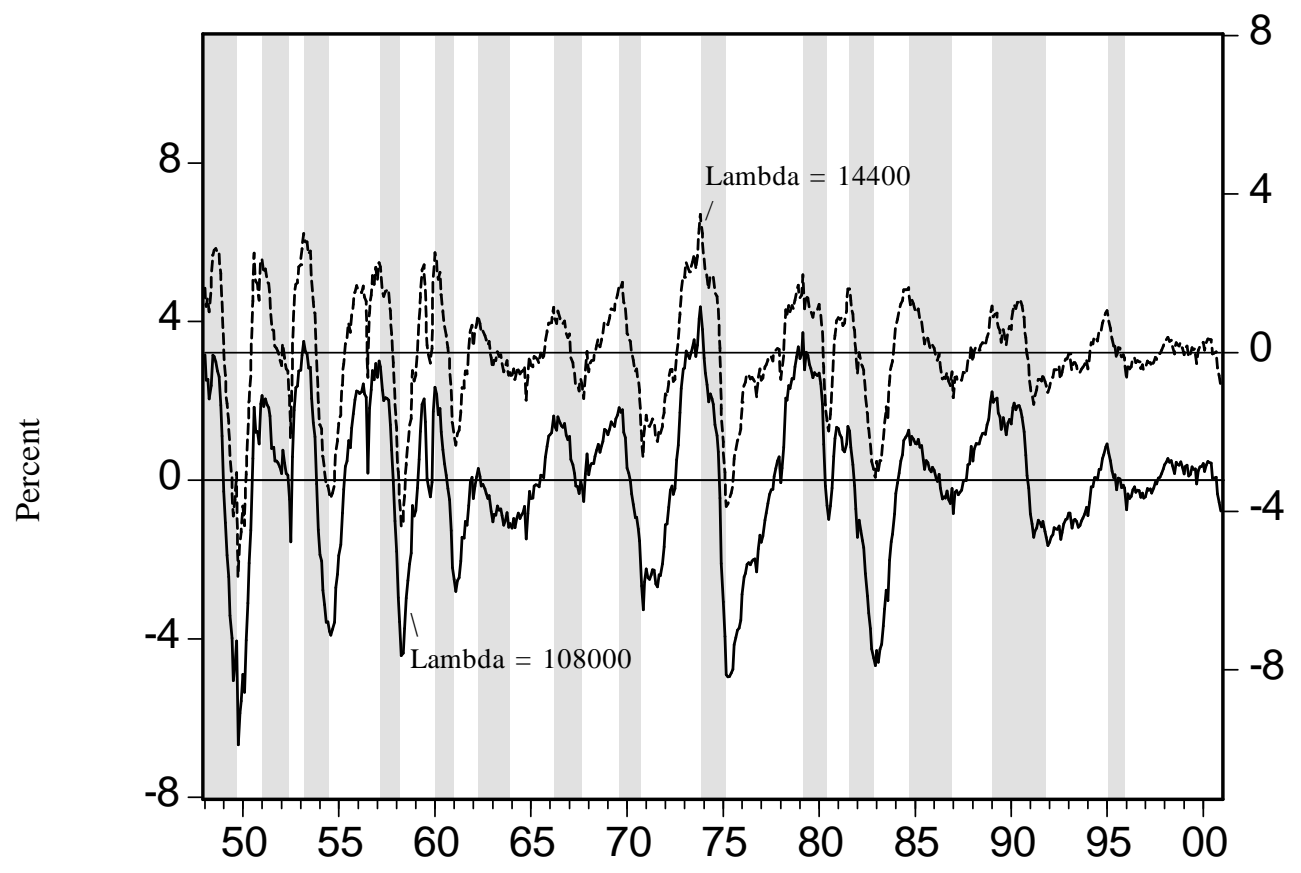

* Shaded areas represent growth cycle recessions based on the U.S. Coincident Index 
Chart 14: U.S. Coincident Index and Heuristic Trend Proposed by Rotemberg (1999) Monthly, 1948-2000*

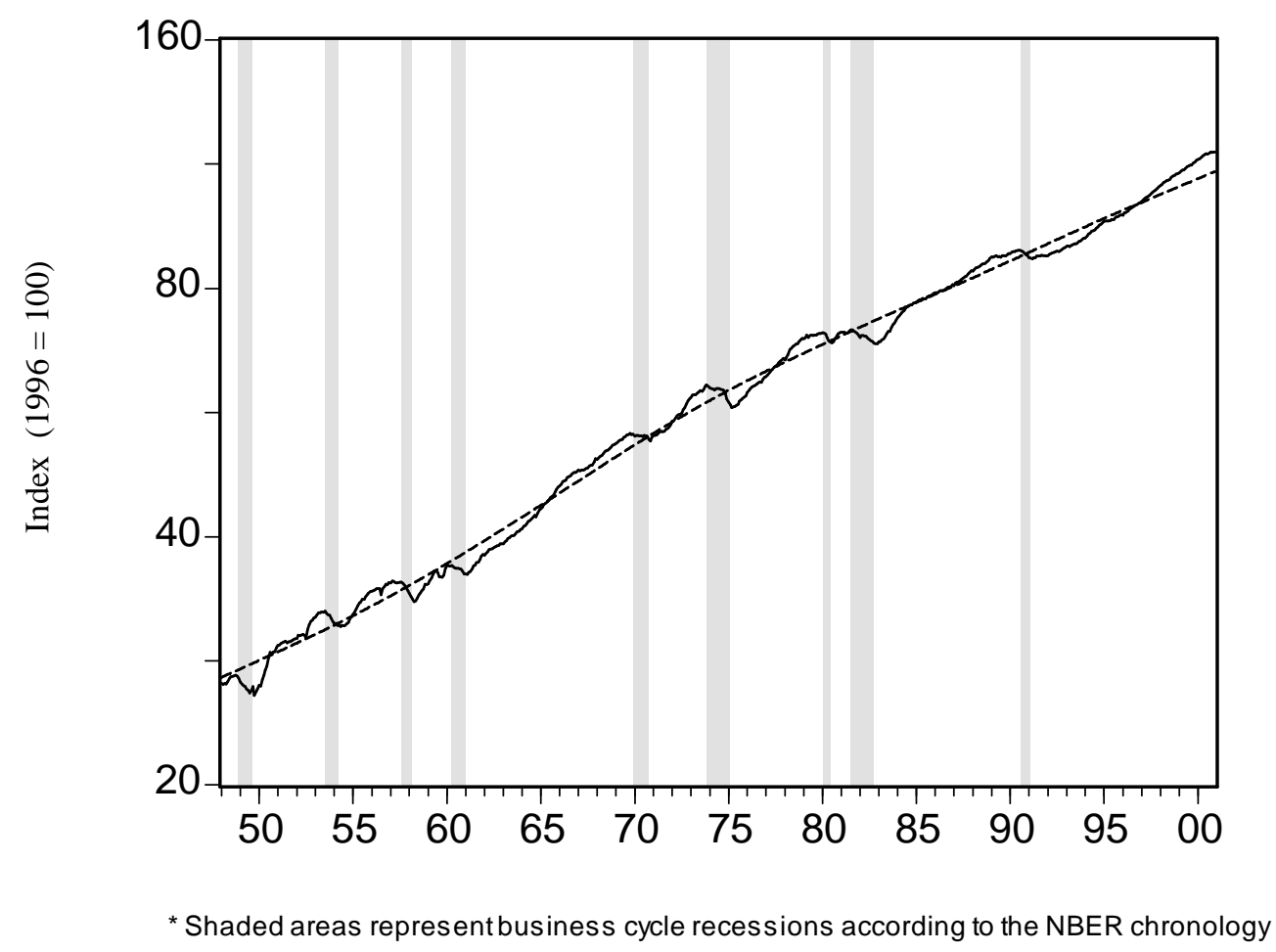

Chart 15: U.S. Coincident Index

Deviations from Heuristic Trend Proposed by Rotemberg (1999)*

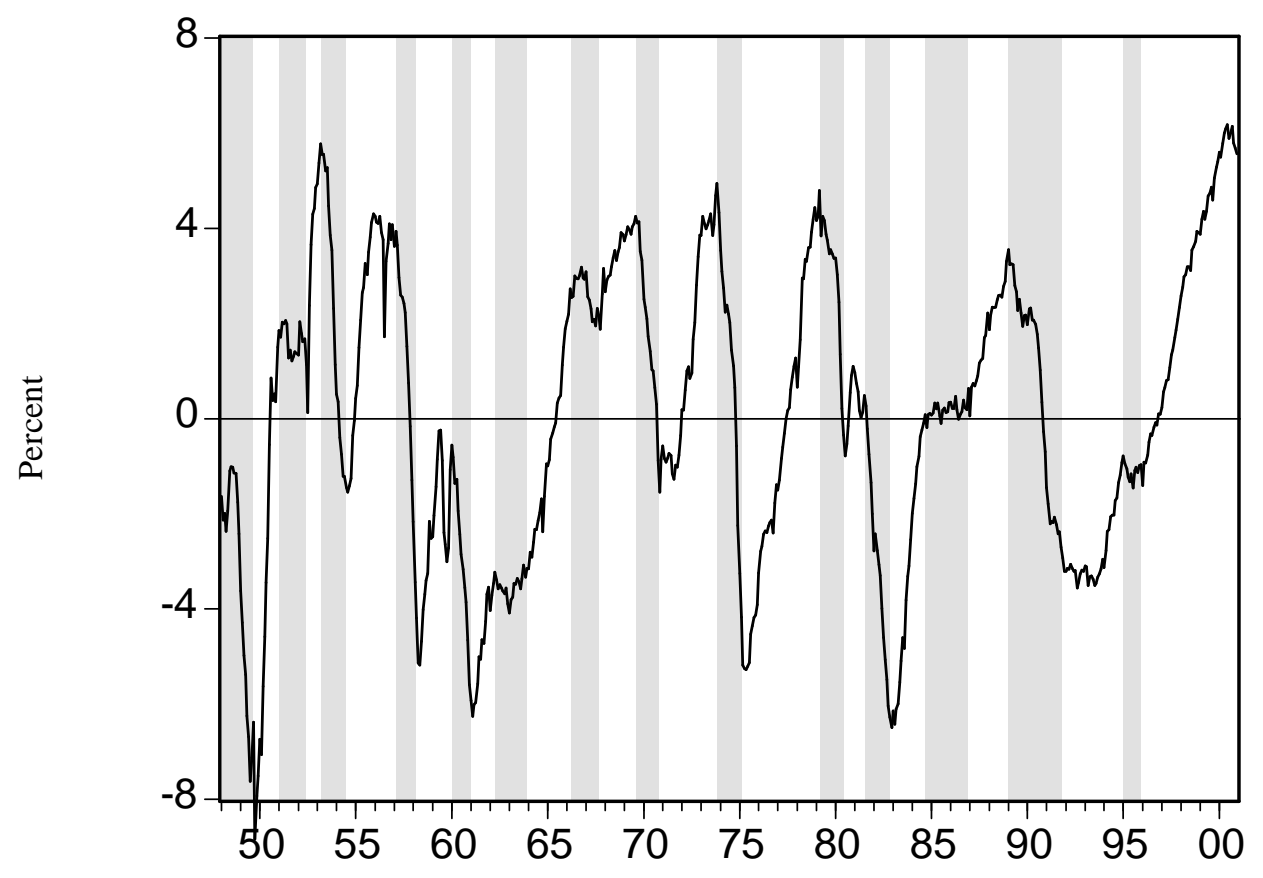

* Shaded areas represent growth cycle recessions based on the U.S. Coincident Index 
Chart 16: U.S. Coincident Index and Band-pass Trend Monthly, 1948-2000*

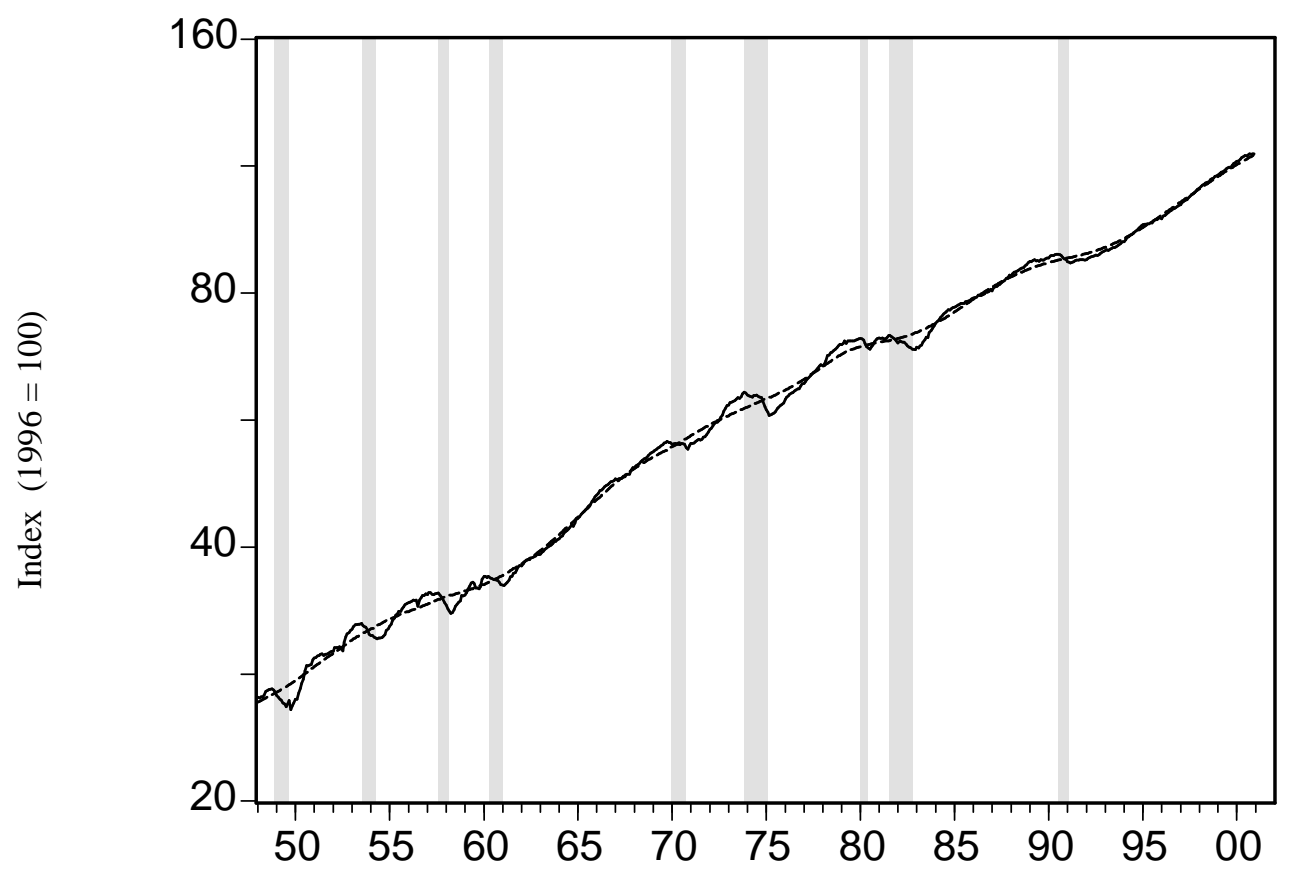

* Shaded areas represent business cycle recessions according to the NBER chronology

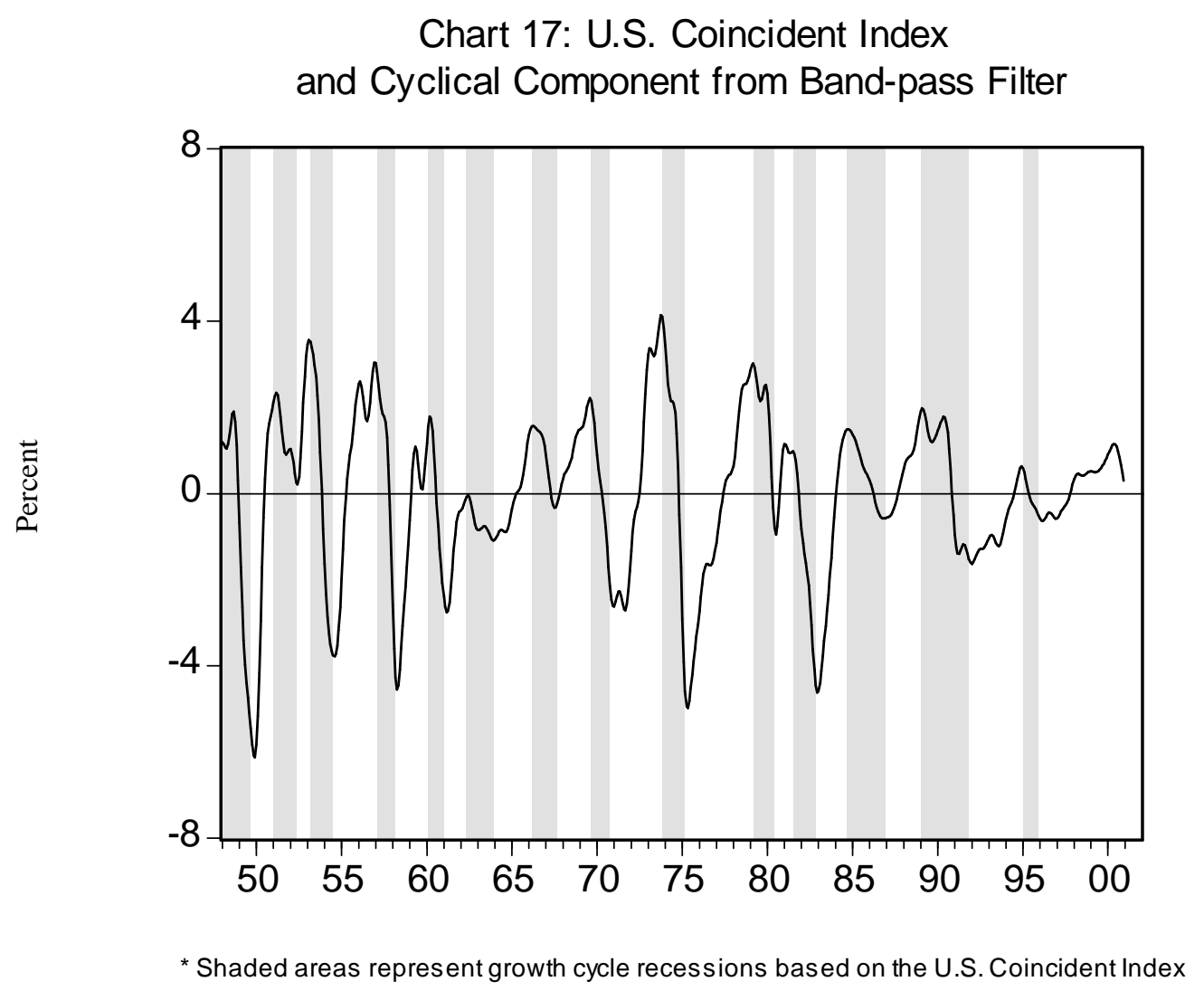

